\title{
A Thermocouple Evaluation Model and Evaluation of Chromel-Alumel Thermocouples for High-Temperature Gas-Cooled Reactor Applications
}

by

Bev. W. Washbum

Manuscript completed: March 1977

Issued: April 1977

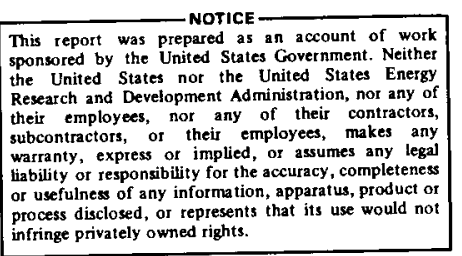

infringe privately owned rights.

Prepared for the US Nuclear Regulatory Commission Office of Nuclear Regulatory Research 


\section{DISCLAIMER}

This report was prepared as an account of work sponsored by an agency of the United States Government. Neither the United States Government nor any agency Thereof, nor any of their employees, makes any warranty, express or implied, or assumes any legal liability or responsibility for the accuracy, completeness, or usefulness of any information, apparatus, product, or process disclosed, or represents that its use would not infringe privately owned rights. Reference herein to any specific commercial product, process, or service by trade name, trademark, manufacturer, or otherwise does not necessarily constitute or imply its endorsement, recommendation, or favoring by the United States Government or any agency thereof. The views and opinions of authors expressed herein do not necessarily state or reflect those of the United States Government or any agency thereof. 


\section{DISCLAIMER}

Portions of this document may be illegible in electronic image products. Images are produced from the best available original document. 


\section{CONTENTS}

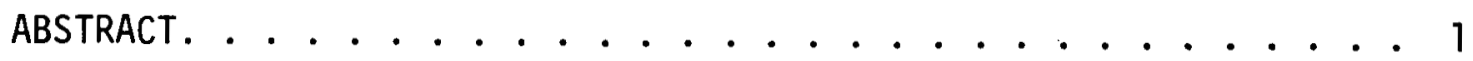

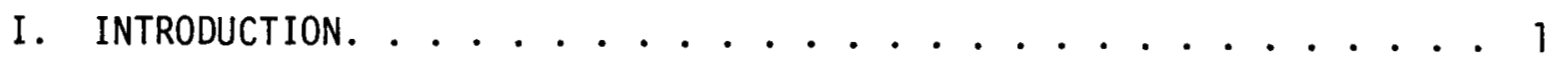

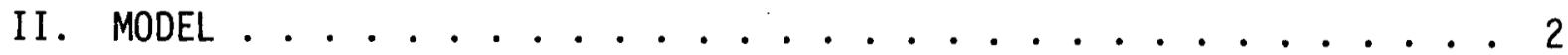

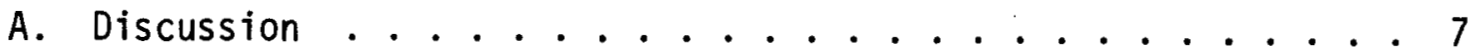

B. Illustrations and Examples............. 8

III. METHOD FOR DETERMINING INHOMOGENEITIES. . ........... 9

IV. FACTORS AFFECTING RELATIVE SEEBECK COEFFICIENTS . . . . . . . 10

V. SPECIFIC FACTORS AFFECTING CHROMEL-ALUMEL PERFORMANCE . . . . . 11

A. As-received Inhomogeneities . . . . . . . . . . 11

B. Short-Range Ordering. . . . . . . . . . . . 12

C. Short-Term and Reversible Effects ........... . 13

1. Cold Working .............. 13

2. Heat Treatment. ............. . 13

D. Non-Reversible Effects. .............. 14

1. 0xidation ................... 16

2. Reduction ................... 18

3. Irradiation ................. . . . . . . . . . . .

E. Factors Affecting Long-Term Performance . . . . . . . . 22

1. General Considerations for Chromel-Alume1 . . . . . 22

2. HTGR-Related Factors ............ . . 26

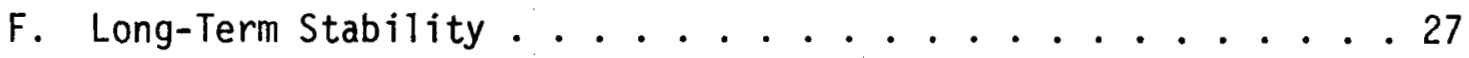

G. Insulation and Sheath ................ 30

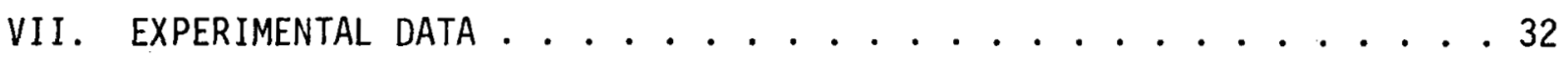

A. Bare Elements . . . . . . . . . . . . . 32

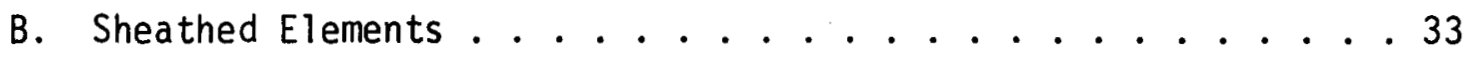

C. Combined Disturbing Effects Including Irradiation ...... 34

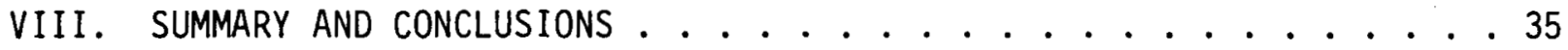

REFERENCES. . . . . . . . . . . . . . . 38 


\section{List of Tables}

I. Irradiation-Induced Composition Changes..................... 20

II. Errors Introduced by Heat Treatments....................... 33

\section{List of Figures}

1. Circuit model........................................ 43

2. Temperature and emf distributions........................ 43

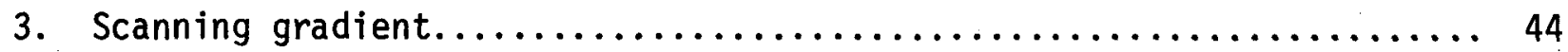

4. Cumulative heat treatment, typical $90 \mathrm{Ni}-10 \mathrm{Cr}$ alloys............ 44

5. Effects of cold work.................................. 44

6. Heat treatment of bare Alumel in air....................... 45

7a. Effect of chromium in $\mathrm{Ni}-\mathrm{Cr}$ alloy on the deviation of thermo-emf

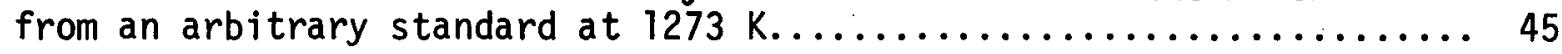

7b. Effect of $\mathrm{Cr}$ in a Ni-Cr alloy (Tophel) on the thermo-emf........... 45

7c. Effect of $\mathrm{Cr}$ content on thermo-emf of $\mathrm{Ni}-\mathrm{Cr}$ alloy vs Pt........... 45

7d. Effect of $\mathrm{Cr}$ content on thermo-emf of $\mathrm{Ni}-\mathrm{Cr}$ alloys vs Pt.......... 46

7e. Effect of $\mathrm{Cr}$ content on thermo-emf of $\mathrm{Ni}-\mathrm{Cr}$ alloy................ 46

7f. Effect of Co on the emf change of Ni-Al alloy (Nial)............ 46

7g. Effect of $\mathrm{Mn}$ on the emf change of $\mathrm{Ni}-\mathrm{Al}$ alloy (Nial) ............. 46

7h. Effect of $\mathrm{Si}$ on the emf change of $\mathrm{Ni}-\mathrm{Al}$ alloy (Nial) ............. 47

7i. Effect of Al on the emf change of Ni-Al alloy (Nial) ............. 47

8a. Cr concentration in the zone of solute depletion in Chromel after heating in air........................................ 47

8b. Comparison of calculated and measured values of thermo-emf drift in $\mathrm{Ni}-\mathrm{Cr}$ alloy..................................... 47

9. Reaction equilibrium: relation between $\mathrm{Po}_{2}$ and temperature........ 48

10. Changes in indicated temperature of 1.0-mm Chrome1-Alume 1 thermocouples in protection tubes and exposed to rich

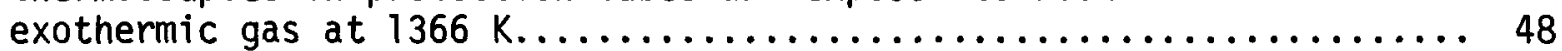

11a. Chromel composition changes by transmutation................... 49

11b. Alumel composition changes by transmutation.................... 49

12a. Change in Seebeck coefficient with $\mathrm{Cr}$ depletion in $\mathrm{Ni}-\mathrm{Cr}$ alloy....... 49

12b. Change in Seebeck coefficient with solute depletion in $\mathrm{Ni}-\mathrm{Cr}$ and $\mathrm{Ni}$-A $\mathrm{l}$ al loys........................................... 50

12c. Change in Seebeck coefficient with $\mathrm{Cr}$ depletion in $\mathrm{Ni}-\mathrm{Cr}$ alloy...... 50

13. Short-range ordering error in Chromel and standard ChromelAlumel error limits.......................................... 51 
List of Figures (cont)

14a. Change in thermo-emf with $\mathrm{Cr}$ depletion in $\mathrm{Ni}-\mathrm{Cr}$ alloy............ 51

14b. EMF and temperature errors with $\mathrm{Cr}$ depletion in $\mathrm{Ni}-\mathrm{Cr}$ alloy (10 wt\% cr initial concentration) ............................ 52

14c. Temperature measurement error for typical solute depletions in Chromel (C) and Al umel (A)................................. 52

15. Thermo-emf errors for solute depletions and nuclear transmutations

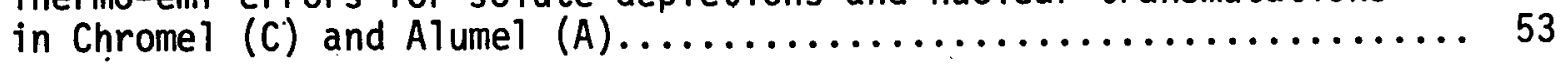

16a. In situ calibration; correct method......................... 53

16b. In situ calibration; incorrect method....................... 54

17. Observed errors for unprotected Chromel-Alumel thermocouples heated in air........................................... 54

18. Observed errors for sheathed Chromel-Alumel thermocouples.......... 55

19. Temperature measurement errors for aluminum depletion in Alumel $(A)$ and chromium depletion in Chromel $(C) \ldots \ldots \ldots \ldots \ldots \ldots . \ldots . \ldots . \ldots$

20. Observed errors for irradiated Chromel-Alumel thermocouples......... 56 


\title{
A THERMOCOUPLE EVALUATION MODEL AND EVALUATION OF CHROMEL-ALUMEL THERMOCOUPLES FOR HIGH- TEMPERATURE GAS-COOLED REACTOR APPLICATIONS
}

by

Bev. W. Washburn

\begin{abstract}
Factors affecting the performance and reliability of thermocouples for temperature measurements in High-Temperature Gas-Cooled Reactors are investigated. A model of an inhomogeneous thermocouple, associated experimental technique, and a method of predicting measurement errors are described. Error drifts for Type K materials are predicted and compared with published stability measurements.
\end{abstract}

\section{INTRODUCTION}

The Los Alamos Scientific Laboratory is carrying out a broad program of research in High-Temperature Gas-Cooled Reactor (HTGR) safety under the direction of the Division of Reactor Safety Research of the U.S. Nuclear Regulatory Commission. A part of that program was the study of the suitability and reliability of thermocouples selected for reactor-safety-related temperature measurements. The program for satisfying this objective encompassed studies of the conductor materials, insulation, sheaths, assembly fabrication, quality control, reliability, and failure modes. This report primarily discusses factors relating to the performance and reliability of Type $K$ conductor materials; however, some data on sheathed assemblies are also included.

A model of a thermocouple with inhomogeneous conductors and an experimental technique for determining the model parameters are presented. Examples are given 
to illustrate application of the model to the prediction of thermocouple measurement errors under service conditions. The inadequacy of conventional thermocouple calibration concepts applied to the quantitive investigation and prediction of stability is discussed. The methods discussed in this report are general and can be applied to other thermocouple investigation and application situations.

\section{MODEL .}

Classical laws relate specifically to linear homogeneous* conductors of different materials connected in a continuous circuit. ${ }^{1}$. These laws relate the net generated emf, junction temperatures, and conductor materials.

Purely thermodynamic reasoning ${ }^{2}$ or the free electron theory of metals ${ }^{3}$ may be used to derive the following equation for the net emf generation of a thermocouple,

$$
E_{\text {net }}=\int_{T_{1}}^{T_{2}} \varepsilon_{1} d T+\int_{T_{1}}^{T_{2}} \varepsilon_{2} d T,
$$

where $\varepsilon_{1}$ and $\varepsilon_{2}$ represent the absolute values of the emf's of the two metals. If the two materials each have one end at $T_{1}$ and one end at $T_{2}$,

$$
E_{\text {net }}=\int_{T_{1}}^{T}\left(\varepsilon_{1}-\varepsilon_{2}\right) d T .
$$

In general, thermocouples are found to exhibit a degree of nonrepeatability and in-service instabilities in their emf-temperature characteristics. These deviations from the ideal performance are believed to result from inhomogeneities in the conductors. Experimental evidence indicates that inhomogeneities range from those present in as-received materials (some of which are fixed and likely to remain so) to those that are created by service conditions such as atmosphere, temperature, nuclear radiation, and time.

*A homogeneous thermocouple is one in which each conductor is homogeneous, in both chemical composition and physical condition, throughout its length. 
A model of the thermoelectric circuit must be developed in order to understand the performance of a nonideal thermocouple in a working environment. Figure 1 presents the elements of a thermocouple circuit that is compatible with the ideal circuit while also including provision for perturbations in the ideal conductors.

The difference voltage, $\Delta e_{n}$, generated in section $n$ is related to the relative Seebeck coefficient for the section and the temperature differential, $\Delta T_{n}$, across the section by

$$
\Delta e_{n}=\left(s_{n}+\Delta s_{n}\right) \Delta T_{n}
$$

and

$$
\begin{aligned}
E_{n} & =\sum_{n=1}^{N} \Delta e_{n}=\sum_{n=1}^{N}\left(s_{n}+\Delta s_{n}\right) \Delta T_{n} \\
& =\sum_{n=1}^{N} s_{n} \Delta T_{n}+\sum_{n=1}^{N} \Delta s_{n} \Delta T_{n} .
\end{aligned}
$$

If conductors $A$ and $B$ are connected at 0 to form a junction, $e_{0}=0$. The relative Seebeck coefficients, $s$, are determined by

$$
s=\varepsilon_{A}-\varepsilon_{B}
$$

and

$$
\left.\begin{array}{r}
s_{n}=\left(\varepsilon_{A_{n}}-\varepsilon_{B_{n}}\right) \\
\Delta s_{n}=\left(\Delta \varepsilon_{A_{n}}-\Delta \varepsilon_{B_{n}}\right)
\end{array}\right\},
$$

where $\varepsilon_{A}$ and $\varepsilon_{B}$ represent the absolute values of the thermal emf coefficients of the conductors $A$ and $B$. 
The emf contribution in each section is determined by the absolute thermal emf coefficient in each wire and the temperature difference across the section. $T_{n}$ corresponds to the temperature of the nth isothermal line intersecting both conductors. The physical lengths of the sections may be variable and should be chosen compatible with the problem parameters and spatial resolution of the data being used to construct the model. Only those portions of the conductors which are subjected to a temperature gradient need be included in a section, i.e., portions of conductors under isothermal conditions, throughout the analysis, may appear as a node between sections of the model. In general, as will be shown later, knowledge of temperature gradients ${ }^{4}$ and their physical location with respect to a reference position along the conductors is required for the performance analysis. This is implied in Eq. (1) although a more explicit expression can be derived.

In the general case, s will vary from point to point with the structure of the conductors. The $s_{n}$, Eq. (1.b), in the first term of Eq. (1) are taken to be the values associated with ideal, homogeneous conductors. Values of $s_{n}$ may be derived from published thermocouple calibration tables or from calibration of actual materials under investigation. Allowance for deviation from standard values should be accounted for if published tables are the reference.

The $\Delta s_{n}$, Eq. (1.b), in the second term of Eq. (1) are obtained by scanning the inhomogeneous regions of the conductors with a steep temperature gradient and measuring the generated emf. The emf is measured relative to either an undisturbed, homogeneous section of the conductor under test or to an undisturbed, homogeneous section of the second material of a thermocouple placed in a reference gradient. The condition of the conductor material in the reference gradient is very important since it can introduce a systematic error into absolute measurements referenced to a standard material.

In inhomogeneous conductors, $s$ will have a spatial dependence relating to both chemical composition and physical condition of the conductors. The $\Delta s_{n}$ account for the variations in the $s_{n}$ due to the inhomogeneities. The $\Delta s_{n}$ may be time and temperature dependent and in some cases they can be dependent on the previous temperature-time history of the section. The $\Delta s_{n}$ coefficients must be absolute or relative to the same material as the $s_{n}$ coefficients. 
For a quantitative evaluation of a given thermocouple in a specific application we must have the coefficients $s_{n}$, the distribution of temperature along the conductors (the temperature gradient is necessary and sufficient if none of the coefficients $s_{n}$ and $\Delta s_{n}$ are temperature dependent), and the $\Delta s_{n}$ (disturbing factors).

Carrying the solution of Eq. (1) through additional steps,

$$
\operatorname{limit}_{N \rightarrow \infty} \sum_{n=1}^{N} S_{n} \Delta T_{n} \longrightarrow \int_{T_{0}}^{T_{N}} s(T) d T,
$$

and

$$
\operatorname{limit}_{N \rightarrow \infty} \sum_{n=1}^{N} \Delta s_{n} \Delta T_{n} \longrightarrow \int_{T_{0}}^{T_{N}^{N}} \Delta s(T) d T,
$$

so

$$
E=\int_{T_{0}}^{T_{N}} \Delta s(T) d T+\int_{T_{0}}^{T_{N}} \Delta s(T) d T .
$$

However, in general,

$$
\begin{aligned}
T & =f(x) \\
d T & =f^{\prime}(x) d x,
\end{aligned}
$$

and

$$
\begin{aligned}
s(T) & =s(f(x))=f^{\star}(x) \\
\Delta s(T) & =\Delta s(f(x))=f_{\Delta}(x),
\end{aligned}
$$

and Eq. (2), becomes

$$
E=\int_{0}^{L} f^{\star}(x) f^{\prime}(x) d x+\int_{0}^{L} f_{\Delta}(x) f^{\prime}(x) d x .
$$


For ideal homogeneous conductors, $s_{n}$ or $s(T)$ would have the same value in all sections under fixed-temperature conditions and would have predictable values of temperature coefficient. The temperature coefficient is usually very small so for ideal homogeneous conductors,

$$
s_{n}+\Delta s_{n}=s=\varepsilon_{A}-\varepsilon_{B}
$$

and from Eq. (2) or (3) we obtain

$$
\begin{aligned}
E & =\int_{T_{0}}^{T_{N}}\left(\varepsilon_{A}-\varepsilon_{B}\right) d T \\
& =\left(\varepsilon_{A}-\varepsilon_{B}\right) T_{N}-\left(\varepsilon_{A}-\varepsilon_{B}\right) T_{0},
\end{aligned}
$$

which is the form of the emf data usually found in thermocouple calibration tables. The significance of the regions of temperature gradient is completely lost in Eq. (4). This also shows that conventional calibration, 5 involving only $E$, $T_{0}$, and $T_{N}$, implicitly assumes that thermocouples are ideally homogeneous. It should be noted that several simplifications are contained in this reduced equation:

1. $\varepsilon$ is not a function of position, although it may be a function of temperature,

2. only two conductors are involved, and

3. each conductor begins at $T_{0}$ and ends at $T_{N}$.

These are the conditions for which the emf-temperature tables are intended.

Equation (4) may also be expressed in terms of physical distance,

$$
E=\int_{0}^{L} f^{\star}(x) f^{\prime}(x) d x,
$$

for ideal homogeneous conductors. This result is not particularly significant in this case since there is no true emf dependence on position.

In general, $f_{\Delta}(x)$ is a function of position, temperature, and time and may be defined as

$$
f_{\Delta}(x)=f(x, T, t),
$$


and Eq. (3)' becomes

$$
\begin{aligned}
E & =\int_{0}^{L} f^{*}(x) f^{\prime}(x) d x+\int_{0}^{L} f(x, T, t) f^{\prime}(x) d x \\
& =\int_{0}^{L} f^{*}(x)\left(\frac{d T}{d x}\right) d x+\int_{0}^{L} f(x, T, t)\left(\frac{d T}{d x}\right) d x .
\end{aligned}
$$

\section{A. Discussion}

We wish to explore the second term in Eq. (5) which causes departure from the ideal homogeneous, classical generated emf. This error term contains, in $f(x, T, t)$,

a. fixed inhomogeneities, a function of position but not temperature or time, and

b. variable inhomogeneities, functions of temperature, position, time, and past history.

It is necessary to identify those effects which contribute to these inhomogeneities, to define their magnitudes, signs, and dependence upon service conditions, time, and past history, and to determine the temperature gradients in the specific application in order to evaluate the measurement performance. Our interest does not relate to obtaining greater measurement precision than manufacturing tolerances can assure. We are concerned about the effects of service conditions and inhomogeneities on the accuracy and reliability of the measurements.

When thermocouples are used in an unfavorable environment or used for very long times, the output voltage may drift with time due to the development of inhomogeneities in the conductors in regions of appreciable temperature gradient. Subsequent recalibration may detect the presence of such inhomogeneities; however, it will not, in general, reveal the true error in the emf generated during previous or subsequent service conditions. The error term in Eq. (5) shows that the true value of the error can only be determined by recalibration conditions which impose the service condition temperature gradient on the conductors. If the degraded region of the material is placed in a uniform temperature zone, Eq. (5) shows that such regions will play no role in generating the emf. If the recalibration temperature gradient in the degraded region exceeds that of the service condition which degraded the Seebeck coefficient, the observed error will be larger than that present under service conditions. Many 
experiments to examine effects of service conditions have been conducted by exposing thermocouples to environments which produce varying degrees of inhomogeneity and then performing conventional recalibration to arrive at related emf errors. Such results are misleading and provide no detailed insight into the inservice data errors. For these reasons we cannot rely on much of the published thermocouple performance data and conclusions based on post-environmental testing and recalibration. We will also see, in a following section, how timeand temperature-dependent inhomogeneities in some conductors can be altered in the recalibration environment. Recalibration may not only produce an incorrect result but also may change the conditions under investigation in the conductors. Many investigations have been conducted with limited objectives to determine thermocouple performance in a specific application. Results of these investigations, meaningful in the intended application, have a very limited usefulness. Equation (5) and the following discussion should provide a firm basis for future thermocouple investigations of more general usefulness in addition to providing a method for evaluating thermocouple in-service performance.

B. Illustrations and Examples

Figure 2 shows some elementary examples of the emf observed along the length of homogeneous and inhomogeneous conductors in assumed temperature profiles. Figure $2 a$ shows the emf distribution along the conductors of an ideal, classical, homogeneous thermocouple in a temperature profile.

Figure $2 b$ shows the emf resulting from an arbitrary inhomogeneity superimposed on the conductors in the same temperature profile. The inhomogeneity in the isothermal regions has no effect on the emf but contributes to the error in the region of the temperature gradient.

Figure 2c illustrates the qualitative variation in observed emf when a temperature profile is moved along the conductors with respect to the position of a fixed inhomogeneity. Alternatively this can be viewed as moving conductors having fixed inhomogeneity with respect to a constant temperature gradient. This also illustrates a case sometimes found in practice. We assume that a homogeneous thermocouple was placed in service in temperature profile 1. The service environment may produce the assumed inhomogeneity. As the inhomogeneity develops, an error in the observed emf will also develop as shown for profile 1 in the emf plot. At this point, one of several events may occur. First, service conditions may change such that the temperature gradient is moved with 
respect to the inhomogeneity and an error in the observed emf as shown by profiles 2 or 3 results. The temperature $T_{0}$ may change (not illustrated) and produce a different temperature gradient in the inhomogeneous region. The error in observed emf will change accordingly. In the event that the inhomogeneity magnitude has a temperature-time dependence, any change in the service temperature will alter the inhomogeneity in magnitude and possibly in physical location. Another event following service under conditions of temperature profile 1 may involve recalibration to determine the error in the in-service temperature observation. The emf profiles in Fig. 2c illustrate the recalibration "errors" which might be observed when using a correct but mispositioned temperature gradient. Profiles 3 and 4 would show an error smaller than the actual error while profile 2 would give a larger error. Similar "errors" can be generated by using a temperature gradient different from that existing in service.

When the inhomogeneity has a temperature-time dependence, the "error," determined by recalibration may be misleading and also the recalibration conditions may alter the inhomogeneity. For example, chromel exhibits a temperatureinduced inhomogeneity, due to short-range ordering, with a magnitude which is almost time independent, regardless of the previous state of the material, in the approximate range of 725 to $925 \mathrm{~K}$. This inhomogeneity in the range of 673 to $723 \mathrm{~K}$ is, in contrast, critically dependent on the time spent in this region and the state of the material will thus depend on the time spent in this temperature region during cooling from higher temperatures or during recalibration.

Thus, in general, meaningful recalibration approaches the impossible and in situ techniques are needed if data are required to greater precision than estabiished error bands.

\section{METHOD FOR DETERMINING INHOMOGENEITIES}

In order to apply the model, we need quantitative information relating causes to spatial changes in conductor Seebeck coefficients. The effect of individual causes or service conditions, such as cold work or irradiation, can be impressed on samples of the conductors and the samples can be subsequently scanned with a traveling thermal gradient to determine the resulting spatial variation in absolute or relative Seebeck coefficient.

A method for measuring the inhomogeneity component, $\Delta s_{n}$, Eq. (1.b), or $f(x, T, t)$, Eq. (5), has been described by Fenton. 6 In this method, the scanning 
gradient, $A$, Fig. 3 , is moved along the conductor, $X-Y$, under test. The reference gradient, $B$, is fixed with respect to the conductor. The emf between points $X$ and $Y$ is proportional to the mean $\Delta s$ of the portion of the conductor in gradient $A$ with respect to the portion of the conductor in reference gradient $B$. If $T_{1}$ and $T_{2}$ are known and constant throughout the interval of the gradient scan, $\Delta s(x)$ can be derived from the measured emf. The conductor may be a single material or two materials joined to form a junction at $Z$. In the latter case the measured emf will be relative to material $Y-Z$ in gradient $B$.

The conductor in the reference gradient $B$ must be undisturbed and homogeneous. From Eqs. (1) or (5), for a single material, $X-Y$, over the length of the temperature gradient,

$$
\overline{\Delta s}_{X-Y}(x)=\frac{E_{X-Y}(x)}{\left(T_{2}-T_{1}\right)}=\overline{\Delta \varepsilon_{X-Y}}(X),
$$

and for two materials joined at $Z$,

$$
\begin{aligned}
& \frac{E_{X-Y}(x)}{\left(T_{2}-T_{1}\right)}=\varepsilon_{X Z}(x)-\varepsilon_{Y Z}(x)+\Delta \varepsilon_{X Z}(x) \\
& \overline{\Delta s}_{X-Y}(x)=\frac{E_{X-Y}(x)}{\left(T_{2}-T_{1}\right)}-\left(\varepsilon_{X Z}(x)-\varepsilon_{Y Z}(x)\right) .
\end{aligned}
$$

It is important that the scanning process, including $T_{2}$, scanning time and conductor handling, be conducted in a manner which assures that the inhomogeneity of the conductor under test is not altered. The distance spanned by the gradient should be compatible with the spatial dependence of the inhomogeneity.

\section{FACTORS AFFECTING RELATIVE SEEBECK COEFFICIENTS}

Disturbing factors may cause the relative Seebeck coefficients, $s_{n}$, to deviate $\left(\Delta s_{n}\right)$ from their nominal or previous values as the result of changes in chemical composition and physical condition throughout the length of the conductors. Some disturbing factors are: ${ }^{6}$

1. Factors fixed in the material as received (likely to remain fixed in service)

a. batch-to-batch variation in alloys (homogeneously distributed) 
b. local variations in impurity and alloy composition (inhomogeneously distributed)

c. absorption, by solution or chemical combination, of materials during fabrication, handiing, etc.

d. loss of constituents by selective evaporation or chemical attack during fabrication, handling, etc.

2. Metallurgical changes (function of temperature and time; imposed systemmatically on the material)

a. work hardening, annealing

b. recrystallization

c. solution/precipitation of constituents

d. ordering effects

e. dislocations (permanent or temporary)

f. nuclear transmutation

3. Factors imposed by the environment

a. elastic strain

b. static pressure

c. magnetic flux

d. absorption, by solution or chemical combination, of materials from the environment

e. loss of constituents by selective evaporation or chemical attack.

\section{SPECIFIC FACTORS AFFECTING CHROMEL-ALUMEL PERFORMANCE}

Chromel-Alumel thermocouples have been proposed for use in the HTGR systems. We are interested in evaluating factors which could affect the calibration, installation, and in-service performance of these thermocouples in this application. For this study we have reviewed and evaluated experimental findings reported in Refs. 6 through 60. A summary of information on factors believed to be important to HTGR applications is presented in the following sections. A. As-Received Inhomogeneities

As with other alloys, as-received Chromel-Alumel will be subject to all disturbing factors in 1 above. No quantitative information or test results have been found which would separate and identify the contribution of each factor to thermocouple error. However, reported data establishes probable limits on the effects of these factors. Measurements ${ }^{7}$ indicate maximum variations of $1.3 \mathrm{~K}$ from the standard tables, with test repeatability of $\pm 0.5 \mathrm{~K}$, in as-received 
Chromel-Alumel thermocouples tested in a gradient of approximately 30-mm length between isothermal conditions of $423 \mathrm{~K}$ and $298 \mathrm{~K}$ imposed on the conductors. This is an average gradient of $4.2 \mathrm{~K} / \mathrm{mm}$. Other data ${ }^{6}$ indicate that as-received inhomogeneities would not contribute uncertainties greater than $0.05 \mu \mathrm{V} / \mathrm{K}$ in gradients up to $20 \mathrm{k} / \mathrm{mm}$. The Alumel conductor contributed about $80 \%$ of the total variation. These latter uncertainties are relative to a stable reference temperature gradient along a fixed segment of the test sample and are believed to be representative of the errors associated with factors $1 \mathrm{~b}$ through $1 \mathrm{~d}$, inhomogeneously distributed. The errors referred to standard emf tables are believed to be representative of errors produced by factors 12 through $1 d$, both homogeneously and inhomogeneously distributed. These results give some insight into the relative magnitude of as-received batch-to-batch emf variations compared to variations within a given batch. Also, the possibllity of batch calibration is suggested as a means of reducing, for some applications, measurement uncertainties.

\section{B. Short-Range Ordering}

Chromel, in the temperature range of approximately $475 \mathrm{~K}$ to $875 \mathrm{~K}$, exhibits time dependent, positive emf errors or changes $(\Delta s)$ in the Seebeck coefficient as shown in Fig. 4. The magnitude of the change in the 473 to $723 \mathrm{~K}$ range depends on both temperature and time at temperature (temperature-time).

In the range 473 to $673 \mathrm{~K}$ the development of the inhomogeneity is very slow, requiring periods of several weeks to months to attain equilibrium. It has been shown ${ }^{8}$ that the electrical resistivity of $\mathrm{Ni}-10 \mathrm{Cr}$ alloy increases toward an equilibrium value which is independent of thermal history in the temperature range 553 to $773 \mathrm{~K}$. The contention that this increase relates to the degree of short-range ordering is supported on theoretical grounds. ${ }^{9}$ Burley ${ }^{10}$ used these

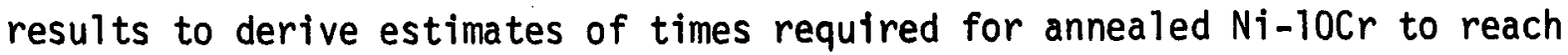
equilibrium resistivity values at temperatures in the range between 550 and 770 $K$. These estimates agree with times required for the change in Seebeck coefficient to equilibrate during heat treatment as reported by Fenton. 6

From 723 to $873 \mathrm{~K}$ the state is nearly independent of time. The metallurgical process responsible for this change at $723 \mathrm{~K}$ was investigated 6,11 and short-range ordering was found to be the mechanism. Figure 4 indicates an apparent complete absence of short-range ordering in Chromel (90Ni-10Cr) heated at $973 \mathrm{~K}$. However, rapid quenching is necessary following heat treatment at $973 \mathrm{~K}$, otherwise some short-range ordering and associated error or change in Seebeck 
coefficient will take place in the wire during cooling. It has been suggested ${ }^{12}$ that this change in the Seebeck coefficient may also be sensitive to the previous mechanical treatment of the material. It is believed that this may account for differences found in the short-range ordering characteristic of different samples of materials which were apparently fully annealed prior to testing.

Changes in the Seebeck coefficient, $\Delta s$, will occur in sections of the Chromel conductor during heat treatment, calibration, use, or recalibration in accordance with the temperature-time characteristics of Fig. 4.

c. Short Term and Reversible Effects

Factors affecting the Seebeck coefficient may be homogeneously or inhomogeneously imposed on the conductors during fabrication, calibration, or installation of the thermocouple. Some of these imposed effects can be altered or reversed.

1. Cold Working

Tests $^{6}$ on Chromel and Alumel which had been cold-worked by stretching and swaging have indicated changes in the Seebeck coefficients as shown in Fig. 5. The sign reversal with increasing elongation in Alumel is unique among the common thermocouple materials. Alumel recovers from cold work at room temperature; the effects of $25 \%$ elongation are essentially recovered after six months' storage.

In Chrome 1 , recovery from cold work starts at approximately $623 \mathrm{~K}$ and is complete at $723 \mathrm{~K}$.

Accidental cold work likely to occur in practice can be represented by localized elongations less than $20 \%$.

\section{Heat Treatment}

The temperature-time characteristics for Chromel in Fig. 4 represent the changes in Seebeck coefficient during heat treatment. Reversals in slope indicate the presence of more than one effect or a reversible effect. The coefficient change in Chrome 1 between 553 and $723 \mathrm{~K}$ is due to short-range ordering.

If short-range ordering were the only error-producing factor of interest, a short-time isothermal anneal at 723 to $773 \mathrm{~K}$ should produce a relatively stable emf provided that this aging temperature is not subsequently exceeded. There would, however, be an emf error associated with the degree of short-range order produced by such aging. A short-time isothermal anneal at 923 to $973 \mathrm{~K}$, where oxidation effects will be negligible, followed by a rapid quench should leave 
the material in the ground state and recovered from any cold-work effect originally present. The Seebeck coefficient error-vs-temperature characteristics of Fig. 4 and the potential for grain boundary attack should be considered before Chromel is heat-treated.

The mechanism for the change around 923 to $973 \mathrm{~K}$, for longer treatment times, has not been investigated. Although the onset of oxidation effects is generally considered to be in the 1148 to $1173 \mathrm{~K}$ region, this mechanism may be starting to influence the change in Seebeck coefficient around 900 to $973 \mathrm{~K}$ as grain boundary attack has been observed in Alumel at $723 \mathrm{~K}$ in $10-20$ vol\% oxygen-argon mixtures and in both Alumel and Chromel at $923 \mathrm{~K}$. In free static air, local penetration of grain boundaries in both alloys has also been observed after 30 min at $923 \mathrm{~K} .{ }^{13}$ Heat treatment has been used to show the effects of short-range ordering and cold work; ${ }^{6}$ at $20 \%$ elongation these effects are separate and additive.

Bare Alumel exhibits temperature-time dependent changes ${ }^{6}$ in the Seebeck coefficient as shown in Fig. 6; changes due to heat treatment, like those for cold working, are anomalous. Retesting after five month' 'storage at room temperature indicated a decrease in coefficient changes for samples treated at 723 to $873 \mathrm{~K}$, an increase in changes between 623 and $723 \mathrm{~K}$ and finite effects at $623 \mathrm{~K}$ where none were seen prior to aging. Mineral insulated Alumel, in contrast, did not show changes in the Seebeck coefficient with heat treatments up to $1023 \mathrm{~K}$ for periods of 90 days.

D. Non-Reversible Effects

Metallurgical changes may be imposed inhomogeneously on the materials during fabrication or service. Impurities or contaminants in the materials used in the assembly or in the service environment may cause changes in the alloy solutes during use. The thermoelectric emf of an alloy can be altered by changes in chemical composition such as the addition of an element unintentionally (contamination), or the removal of an element by preferential oxidation or volatilization.

Figure 7 shows effects of solute content on the thermoelectric emf of nickel-chromium and nickel-aluminum allows. These data indicate magnitude and sign differences in the relationship between emf variation and solute content changes in the various alloys. However, some observations, useful in the interpretation of test results, can be made from these data.

The effect of variations in chromium content is less at low temperatures $(523-873 \mathrm{~K})$ than at high temperatures $(1273 \mathrm{~K})$. Drift tests on Chromel under 
conditions where the chromium content is altered would be expected to show smal1er emf changes or smaller temperature errors at low temperatures than at high temperatures. When the rate of solute depletion is temperature dependent, a given change in chromium concentration requires more time at low temperatures than at high temperatures. Since the slope of the emf vs concentration changes sign with concentration, the behavior of the emf change with solute depletion will depend on the initial solute content. The chromium content corresponding to zero slope is greater at high temperature than at low temperature. If solute depletion were the only mechanism causing the emf to change, the emf drift would be expected to depend on the initial solute content and the temperature. If the Alumel is assumed to be stable, the Chromel-Alumel (90Ni-10Cr) thermocouple emf is expected to initially increase and then decrease at temperatures up to about $1275 \mathrm{~K}$ as the solute depletes. The change from increasing to decreasing emf would take a much longer time at lower temperatures, assuming that the solute depletion is temperature dependent. This seems straight forward; however, not all published drift data behave in this manner which suggests that other mechanisms, environmental factors, solute depletion in the Alume1, or test techniques are involved.

Fiqures $7 f$ through $7 i$ show the effect of the solute concentrations on the thermoelectric emf in nickel aluminum alloys. All of the solutes, A1, Co, Mn, and $\mathrm{Si}$, have a significant effect on the emf. Data on the reduction of these solutes in various environments have not been compiled and reviewed; most reported investigations have concentrated on the Chromel alloy. Error-temperature relationships could also be developed for prediction of error contributions with solute depletion in Alumel. Selective oxidation of aluminum and manganese in Alumel are believed ${ }^{14}$ to contribute to the changes in emf-temperature characteristics. Analysis of one Alumel sample, before and after $9500 \mathrm{~h}$ at $1223 \mathrm{~K}$ in air, indicated $1.5 \mathrm{wt} \%$ and $1 \mathrm{wt} \%$ reduction in aluminum and manganese, respectively in the sub-scale oxide layer. The composition of the unoxidized core was believed to have not changed; however, no confirming data were obtained on possible related thermoelectric emf changes. Tests for composition changes, while informative, should not be regarded as conclusive evidence of thermoelectric performance. In nonuniform oxidation, both the composition and the homogeneity of the conductor change during the formation of an oxide. In the case of uniform oxidation, the presence of oxide alone does not cause a thermoelectric change. Metallurgical studies must therefore be accompanied by thermoelectric studies. 
Some constituents in the alloys play important roles in the service environmental test performance of the thermocouple aside from making the temperature-emf characteristic follow a specific calibration within an established tolerance. Several alloy compositions which meet the Type $K$ calibration are available and these alloys have been called, perhaps too loosely, Chromel-Alumel, grades of Chromel-Alume1, or simply Type $K$ in reports of investigations. We therefore cannot make detailed interpretation and comparisions of many published test results.

It should be mentioned that other base metal combinations could provide improved stability over that of the Type $K$ thermocouples but many of these combinations have emf-vs-temperature characteristics which depart from the Type $K$ curve. There has been reluctance to change from the Type $K$ characteristic and much work has been done trying to improve stability while conforming to the existing emf characteristic.

1. Oxidation

No data for temperature-time effects of oxidation on the Seebeck coefficients, comparable to that in Figs. 4 and 6 , were found during this investigation. Oxidation is generally considered to occur at temperatures above $1148 \mathrm{~K}$. Test data, though indicating widely varying results particularly above $1148 \mathrm{~K}$, may be useful in establishing error limits above $923 \mathrm{~K}$.

When an alloy is exposed to an atmosphere containing a partial pressure of oxygen at an elevated temperature, the constituents of the alloy will not oxidize unless the partial pressure equals or exceeds the equilibrium pressure of the oxide. If the partial pressure of oxygen in the atmosphere surrounding the thermocouple is greater than the equilibrium pressure, equilibrium can only be achieved by consuming the oxygen. Thus an atmosphere having an oxygen pressure greater than the equilibrium value will be oxidizing. Depending upon the temperature and partial pressure of oxygen, the atmosphere may be oxidizing to any or all constituents of an alloy.

Nickel-chromium alloys subjected to high temperatures in free air are selfprotecting from continuous oxidation due to the protective nature of the natural oxides which form on the surfaces. Some atmospheres, however, destroy this protective oxide coating or prevent its formation and become corrosive to certain of the alloy constituents.

Long-term emf drifts are caused by the development of compositional inhomogeneities as reactive solutes are depleted by oxidation, in particular by 
internal oxidation and diffusion. On prolonged exposure in air at temperatures in the region of 1073 to $1273 \mathrm{~K}$, Chromel and Alumel alloys produce several oxide layers of differing morphology. This behavior ${ }^{10}$ is characterized by the formation of (a) an outer scale layer of $\mathrm{NiO},(\mathrm{b})$ an internally oxidized zone in which precipitates of oxides of the solute elements appear distributed in a solutedepleted alloy matrix, and (c) ternary oxides which appear in the inner layers of the scales as the result of solid state reactions between internal oxide precipitates and the NiO of the outer scale layer.

The oxidation processes produce oxide layers containing metallic elements in proportions which are different from those of the original alloy and a solutedepleted zone forms in the alloy matrix between the metal/scale interface. Substantial solute concentration gradients appear beneath the internally oxidized zone as the solutes diffuse outward and the porous zone advances inward to replace the alloy matrix consumed in scale formation. The degree of depletion has been estimated by measurement and correlated with the thermal emf drift which it causes. ${ }^{15}$ Figure $8 \mathrm{a}$ shows the measured concentration of $\mathrm{Cr}$ vs distance from the center of a Chromel wire following depletion of the solute during various times of exposure in air at $1223 \mathrm{~K}$. The change in composition of the sample was estimated from the data in Fig. 8a and this change was used to estimate the corresponding emf change using the emf-composition characteristics of Fig. 7a These changes in emf can then be integrated over the temperature gradient to provide the estimate of emf drift shown in Fig. 8b. The limits on the calculated drift reflect uncertainties in measuring the initial chromium content and depletion. A measured drift of Chromel in Fig. 8b is shown for comparison with this calculation; however, this is not the same material sample for which the metallurgical data are presented.

The three controlling factors in oxidation are composition, temperature, and the partial pressure of oxygen. Inhomogeneous composition changes along the conductors are thus related to the temperature distribution and meaningful investigations into long-term emf stability or drift must take this distribution into account.

It has been suggested ${ }^{15}$ that intergranular attack might be inhibited by increasing the solute content beyond that required to cause a transition from an internal to an external mode of oxidation and/or by choice of solute elements that preferentially oxidize to form impervious oxide films. These films would 
substantially inhibit the diffusion processes essential to internal oxidation and would tie up the residual oxygen in the thermocouple assembly. Such alloys have been developed.

An obvious approach is to eliminate the oxygen since intergranular attack has not been observed in the absence of oxygen. However, data 13,16 indicate that low levels of oxygen may be more disturbing than higher levels so it would be necessary to ensure that all oxygen can be removed as a practical consideration. Rapid selective oxidation of chromium in Chromel has been observed ${ }^{17}$ at low oxygen partial pressures in the range 1073 to $1323 \mathrm{~K}$. It is generally concluded that these alloys should not be exposed to marginally oxidizing atmospheres.

Tests, usually referred to as stability or drift tests, under conditions known to be oxidizing show that oxidation produces changes in the Seebeck coefficient which result in positive emf errors relative to the emf generated by unoxidized conductors. The magnitude of the coefficient change exhibits dependence upon time, temperature, pressure, and environment, including impurities or contaminants. In other than a gross sense, the quantitative understanding of the dependencies between causes and effects is far from clear. In many investigations, test conditions designed to isolate and study a particular phenomenon have either not been entirely successful, have ignored the temperature distribution, or have inadvertently involved two or more conditions (causes) whose effects do not correlate.

Oxidation is also believed to be a principal cause of embrittlement failure.

2. Reduction

If the atmosphere surrounding the thermocouple has less oxygen than the reaction equilibrium value, dissociation of oxides in the thermocouple will oocur.

When the partial pressure of oxygen in the atmosphere around the Chrome 1 conductors is almost equal to the partial oxygen pressure of nickel oxide at the temperature of the conductors, the chromium is oxidized while the nickel remains unchanged or is oxidized only to a limited degree, (see Fig. 9). This has been referred to in the art as "green rot" since the selective oxidation of the chromium in the Chromel alloy forms green colored chromic oxide. Partial oxygen pressures which are low enough to cause "green rot" occur in mixtures of carbon monoxide and carbon dioxide or in industrial gases such as nitrogen, hydrogen, 
or helium containing small amounts of moisture as drawn from high-pressure cylinders without special precautions to remove the moisture.

Carbonaceous or sulphur bearing materials attack the Alumel surface more severely than the Chromel surface. After a few hours' exposure at $1073 \mathrm{~K}$ in these environments, a Chromel-Alumel thermocouple will exhibit about $5 \%$ decrease in emf output. 18

A rich exothermic gas atmosphere at $1373 \mathrm{~K}$ is moderately reducing on the oxides and attacks the Chromel-Alumel thermocouple rapidly by preferentially oxidizing the chromium. Reduction causes an emf decrease which can be substantial in the first few hours of exposure followed by a significantly slower rate of decrease at longer exposure times (Ref. 19, p 294). Figure 10 shows time-dependent changes in temperature indications of Chromel-Alumel thermocouples in protection tubes of various types when exposed to a rich exothermic gas at $1366 \mathrm{~K}$.

It is generally recognized that these alloys should not be exposed to reducing atmospheres.

\section{Irradiation}

Thermocouples exposed to neutron radiation may undergo nuclear reactions which alter the composition (radiation transmutation) of the conductors and over a period of time significant changes in composition may result. Thermal and epithermal neutron flux is responsible for the transmutation; fast neutron reactions, in general, cause very little change in composition. Some changes in composition, as shown in Fig. 7 , will alter the emf-temperature characteristic of the thermocouple.

The extent of these nuclear reactions has been calculated ${ }^{20}$ from known physical properties of the isotopes of the elements in some common thermocouple conductors. Table I gives a comparison ${ }^{20}$ of the original composition of Chromel and Alumel and the calculated compositions after ten years of irradiation $\left(3.16 \times 10^{22} \mathrm{n} / \mathrm{cm}^{2}\right)$ at a thermal neutron flux of $1 \times 10^{14} \mathrm{n} / \mathrm{cm}^{2}-\mathrm{sec}$. Figure 11 shows ${ }^{20}$ the calculated transmutation in Chromel and Alumel in this flux as a function of time up to 20 years $\left(6.32 \times 10^{22} \mathrm{n} / \mathrm{cm}^{2}\right)$. These data indicate that Chromel is relatively stable; however, a reduction of approximately $0.3 \%$ in Chromium content at $6 \times 10^{22} \mathrm{n} / \mathrm{cm}^{2}$ was calculated. This reduction, if homogeneously imposed, can produce changes in the Seebeck coefficient, Fig. 12, which vary with temperature and which may result in a positive error of several degrees at temperatures of 973 to $1373 \mathrm{~K}$ if the transmutation occurs in a region of temperature gradient. 
TABLE I

IRRADIATION-INDUCED COMPOSITION CHANGES ${ }^{20}$

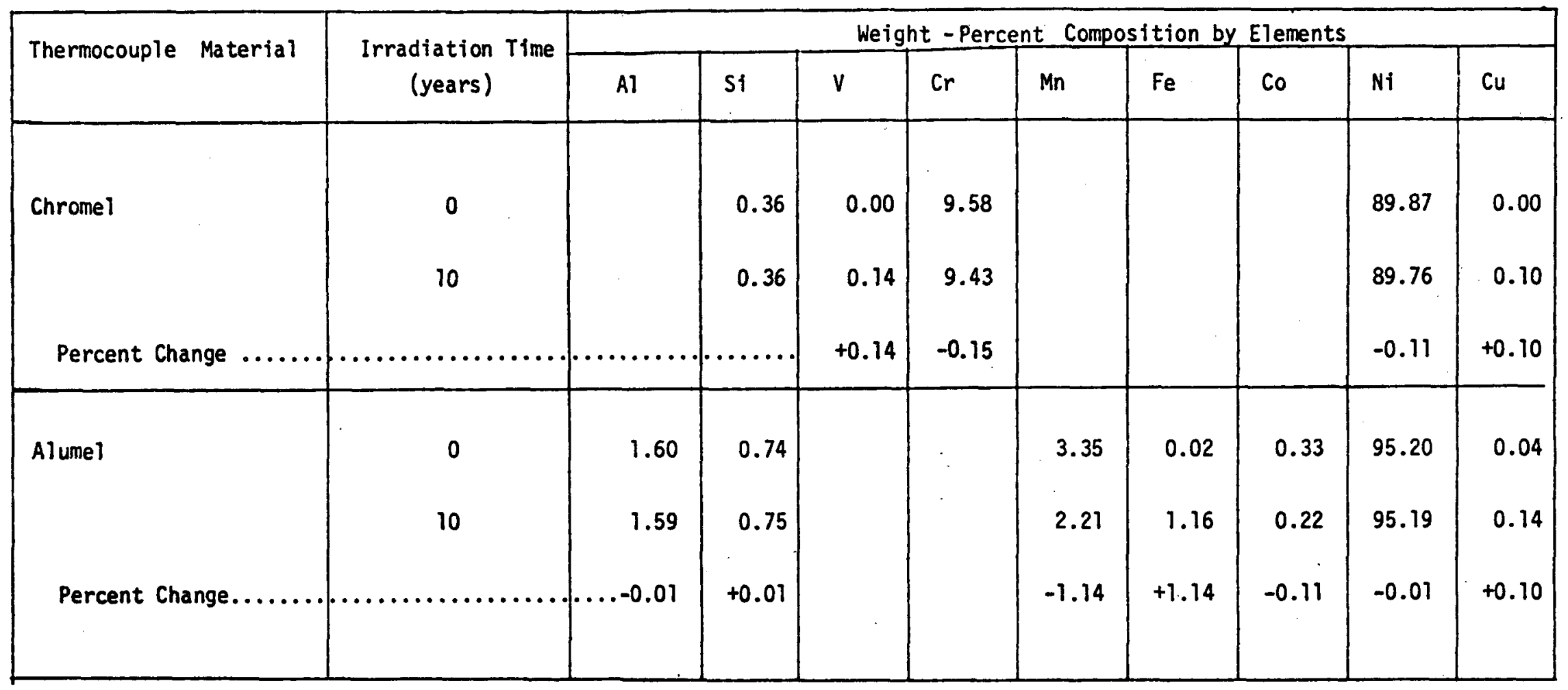


The effects of the calculated solute changes in Alumel are believed to be potentially much more serious. Information on the effect of variations in silicon content in a range of less than 1 wt\% has not been found; however, data for the emf dependencies of other elements in Table I were used to estimate expected temperature errors in Chromel-Alumel thermocouples. Excluding the effects of changes in silicon, copper and iron content, the following estimates of measurement error were made for 20 years' exposure to a total dose of $6 \times 10^{22}$ $\mathrm{n} / \mathrm{cm}^{2}$, conservatively assuming that the affected regions of the conductors are in the temperature gradient.

\begin{tabular}{cc} 
TEMPERATURE $(K)$ & ERROR $(K)$ \\
\hline 533 & -14 \\
811 & -37 \\
1089 & -63 \\
1367 & -92
\end{tabular}

For those solutes on which no information has been located, the following qualitative effects on the above errors were derived using data in Refs. 21 and 22:

a. increase in silicon $(0.74$ to $0.75 \%$ ) may increase errors slightly (increases of 0.5 to $3.0 \mathrm{~K}$ are estimated between 533 to $1367 \mathrm{~K}$ ),

b. increase in copper $(0.04$ to $0.32 \%$ ) may reduce errors slightly (reductions of 2 to $10 \mathrm{~K}$ are estimated between 673 and $1273 \mathrm{~K}$ ) and

c. increase in iron $(0.02$ to $2.0 \%)$ may reduce errors slightly below 675 to $775 \mathrm{~K}$ but is expected to increase significantly errors above $873 \mathrm{~K}^{21}$

While these predicted errors may seem quite large, it is important to be mindful of the temperature gradient assumption and to observe that the calculated errors depend on the assumed initial solute concentrations and the relationships in Figs. 7a-7i. Data in the 1 terature indicate a relatively wide range of values for initial solute contents in "Type $K$ " thermoelements (see Refs. 23, p. $126 ; 10 ; 15 ; 24 ; 25$; and 26$)$ and the emf changes vs changes in solute contents shown in Figs. $7 a-7 i$ are sensitive to this initial content. It should not be surprising that error calculations differ from experimental values and that experiments, with or without radiation, give a variety of different results. 
This study has found no experimental error studies which reported knowledge of the initial solute contents of the actual materials under investigation.

Somewhat to the contrary, there are statements to the effect that existing evidence assures that thermocouples are little affected by irradiation (Ref. 27, p. 140) and that Chrome1-Alumel thermocouples have performed satisfactorily up to $5500 \mathrm{~h}$ with neutron fluences of $6 \times 10^{20} \mathrm{nvt}$ fast and $2 \times 10^{21} \mathrm{nvt}$ thermal. ${ }^{28}$ Al1 bases for these beliefs have not been reviewed; however, review of available references does not substantiate such belief. Understanding of the decalibration effect of solute depletion may be incomplete if sound experimental evidence shows little effect due to irradiation. For some materials, postirradiation composition agrees with calculated values while the extent of decalibration due to these changes in composition could not be predicted (Ref. 29 , p. 29.1).

E. Factors Affecting Long-Term Performance

We are concerned with errors and failures caused by changes in the materials over the lifetime of the installation. Any factor which causes the depletion of solutes in the conductors will have an adverse affect on service life. Among such factors are the presence of impurities or contamination which may cause selective oxidation of the solutes or reduction of protective oxides, oxidizing or reducing gases or compounds in the environment to which the conductors are exposed, and nuclear radiation.

1. General Considerations For Chromel-Alumel

Chromel-Alumel thermocouples are acceptably stable in clean, freely oxidizing atmospheres such as normal air up to about 1075 to $1175 \mathrm{~K}$ over extended periods of time. It might seem that similar performance could be attained in other atmospheres by protecting the thermocouple with a tube or sheath. This has not always been true. In fact, performance of sheathed thermocouples has been very poor ${ }^{23}$ in many cases, relative to performance in air, especially above $1123 \mathrm{~K}$.

One of the most common causes of emf deterioration has been impurities or contaminants inside the assembly. When heated, these contaminants become oxidizing or corrosive. Investigation ${ }^{23}$ indicates that both oxidation and reduction may occur in protected (swaged) assemblies to the extent that the standard Type $K$ error limits $( \pm 2.2 \mathrm{~K}, 255$ to $550 \mathrm{~K} ; \pm 3 / 4 \%, 550$ to $1533 \mathrm{~K})$ are frequently exceeded, particularly above $1123 \mathrm{~K}$. 
In a protected or swaged assembly, oxygen, available from entrapped air or refractory insulators, may contribute to the stability problem. The substoichiometric character of refractory oxides such as $\mathrm{BeO}$ and $\mathrm{MgO}$ is responsible for free atoms of oxygen. Fast neutron bombardment can also free oxygen from the oxides. With an inadequate air supply and stagnation in the tube, oxygen is initially depleted by normal oxidation of the surfaces. When the critical low partial pressure of oxygen is reached, intergranular oxidation of the Chromel begins. In a completely sealed tube this action can be supported by oxygen contained in oxidized surfaces or insulation inside the protective enclosure. It has been shown ${ }^{13,16}$ that there is no evidence of $\mathrm{Ni}$-alloy degradation in oxygen-free argon environments up to $923 \mathrm{~K}$; however, the attack can be severe for a few $\left(<1\right.$ to 20) v01\% $0_{2}$ at 725 to $925 \mathrm{~K}$. Both Chromel and Alumel are attacked in this range; however, most investigations $15,17,30,31$ seem to have concentrated on the preferential oxidation of chromium in Chromel as a cause of calibration drift. Such preferential treatment of Chromel at the expense of investigating solute depletion in Alumel does not appear warranted and some evidence in support of this observation will be presented in paragraph F. Preferential oxidation can be significantly reduced $^{17}$ and the thermocouple life extended by excluding oxygen from the protective assembly. The addition, inside the assembly, of a material such as titanium, which has a greater affinity for oxygen than does chromium, has been shown (Refs. $17 ; 27$, p. 16) to reduce preferential oxidation.

An electrical ana $\log ^{26}$ of the thermal emf generation with preferential oxidation present on the conductor surface and test data (with the preferentially oxidized zone removed by grinding) show that the negative error due to 'surficial preferential oxidation' can be reduced but not eliminated by removal of surface oxide; therefore the solute in the core is also affected by the 'preferential oxidation ,'

Discussion in Ref. 32 indicates additional evidence of core attack during surficial oxidation when calibration could not be restored by pickling or machining the surface, but could be restored by subsequent heating at high temperature in a hydrogen atmosphere. This was believed to have removed the oxidation in the core to restore the calibration. Other investigations ${ }^{15}$ of the outer oxidized zone of solute depletion indicate similar positive error dependency on the outer oxide zone produced by heating in air at $1223 \mathrm{~K}$. The oxide formed on the conductor surface does not contribute significantly to emf change 
until just prior to complete oxidation of the element. It should be noted that photomicrograph studies, while informative, do not provide reliable information concerning solute depletion throughout the element.

Some predictions for radiation effects on conductors were introduced in a previous section. Transmutation of the solutes will result in progressive alteration of the thermoelectric emf throughout the service life of the thermocouple. These changes are not linear with time and the resulting emf variations are not linear with composition changes. In general, errors of either sign could be expected at early times in service followed by increasing negative errors toward end of life.

The ability of the conductors to maintain calibration and to withstand thermal cycling is an important requirement. Although this study was primarily limited to the conductors, some mention of thermal cycling-dependent failures of conductors or hot junction grounding connections should be included. Sheathed, insulated assemblies may be of either the grounded or ungrounded junction type. Failure rates tend to be higher with the grounded junction type. ${ }^{33}$ Based on a limited sample of non-irradiated thermocouple assemblies, ungrounded conductor assemblies would be expected to survive about three times more thermal cycles than grounded conductors ${ }^{33}$ between 1255 and $645 \mathrm{~K}$ at rates of approximately $100 \mathrm{~K} / \mathrm{sec}$. Under these thermal cycling conditions, Chromel-Alumel thermocouples with ungrounded conductors average about $1.9 \times 10^{4}$ cycles to failure. Therma 1 cycling of ungrounded units between 923 and $703 \mathrm{~K}$ produced no failures at $1.5 \mathrm{x}$ $10^{4}$ cycles. Ho data were given on calibration stability under these cycling conditions.

This performance should be quite acceptable in most applications, however, these findings are for assemblies which have not undergone significant disturbances in structural long-range order as might be induced by fast neutron bombardment.

Diffusion of the elements of the measured atmosphere into the protected area is of concern. Figure 10 shows errors observed with several protective assemblies in a reducing atmosphere of rich exothermic gas at $1365 \mathrm{~K}$. Carbon monoxide, carbon dioxide, and nitrogen, hydrogen, or helium containing small amounts of moisture must be kept out of the assemblies. While diffusion may have occurred in some instances, this condition is believed to be unnecessary to cause corrosion in protective tubes. ${ }^{17}$ Clean assemblies have exhibited selective oxidation 
of the chromium in a critical temperature range of approximately 1075 to $1315 \mathrm{~K}$. This degradation was found to correlate with the protective tube length-todiameter ratio.

Embrittlement is believed to be determined in part by disturbances in the structural (crystalline) long-range order of binary and ternary conductor alloys. Such disturbances, induced by fast neutron bombardment over a period of time, would resuit in structural weakness which could contribute to common mode failure if the affected materials were mechanically disturbed.

Complete failure by fracture of thermocouple conductors has occurred in simulated reactor environments. ${ }^{13}$ Failures have also occurred in reactor service but it is not known if precise causes have been determined. Failure by fracture can occur as a result of a grain boundary embrittlement while such embrittlement has 1ittle effect on emf. (This embrittlement can be caused by sulphur attack, preferential grain boundary oxidation which produces films of either alumina or chromium oxide in the grain boundaries, or by precipitation of chromium carbide similar to "weld decay" in austenitic stainless steels. Fast neutron bombardment also contributes to embrittlement.) One drift test ${ }^{13}$ reported 1 ittle emf drift after several thousand hours in a furnace; however, this thermocouple disintegrated upon handling following removal from the furnace. This suggests that thermocouples which appear to be indicating temperatures acceptably well may suddenly experience gross failure (common mode) when subjected to mechanical shock.

A simple model was used to predict possible emf behavior following conductor failure in the presence of non-ideal insulators. Results indicate that the emf change may be of either polarity thus making the observed temperature high or low. This change is not necessarily of sufficiently large magnitude so as to make the indication obviously suspect and such gross error behavior (Refs. 27 , p. $140 ; 34 ; 35$ ) should not be relied upon to identify failures. The magnitude and polarity of the erroneous indication depend on conductor impedance, insulation impedance in the region of the break, which conductor breaks, grounded or ungrounded hot junction, and also on the location of the break with respect to temperature and irradiation profiles along the conductors. Any model used to analyze the effect of conductor fallure would involve the characterization of the insulation, a subject where several viewpojints exist. At least one investigation of a controlled conductor break has been reported (Ref. 27 p. 53). 
This out-of-pile experiment showed that the open circuit thermocouple emf agreed closely with that of a normal thermocouple over a temperature range from 1143 to $1873 \mathrm{~K}$. Another experiment ${ }^{35}$ at $1273 \mathrm{~K}$ using $\mathrm{MgO}$-insulated Chromel and Alumel conductors.. (without hot junction) in a swaged assembly generated an emf accurately matching that of a Chromel-Alumel thermocouple.

Experience indicates that long-term stability in a given environment is dependent on conductor size. This dependence was first observed with units that were not sheathed or protected from the environment. Dahi ${ }^{32}$ reported drifts for 8-to 22-gauge conductors. Results for 28 to 36-gauge wire would be expected to produce larger. drifts because their greater surface-to-volume ratio provides greater sensitivity to environmental reactions. Although some differences in drift would correlate with wire gauge, there has been no special attempt in this study to distinguish these correlations. Reference 23 reported calibration drift of Chromel-Alumel conductors from 20 to 36 gauge. Drift in sheathed assemblies did not correlate with conductor size during tests at $1253 \mathrm{~K}$; however, there was some indication that 20-gauge conductors produced more stable thermocouples than did the smaller gauges. Reference 36 indicated that 24-gauge conductors in 1/8-in.-o.d. sheaths are more stable than conductors of an unspecified gauge (assumed smaller than 24 gauge) in 1/16-in.-o.d. sheaths. The smaller assembly has up to four times the drift observed in the larger assembly at $3473 \mathrm{~K}$.

\section{HTGR-Related Factors}

Impurities in the HTGR coolant, and perhaps He itself, must be kept from the assembly internals. Data for bare conductors 30,37 indicate that emf drifts in flowing "pure" He may be greater than those observed in C or C-Si environments at temperatures of 1033 to $1255 \mathrm{~K}$. Tests in a flowing CO environment 29,30 showed excessive drift or failure after $200 \mathrm{~h}$ at $1093 \mathrm{~K}$. Tests at 923,1023 , and $1123 \mathrm{~K}$ in flowing 95 vol\% $\mathrm{CO}_{2}, 5$ vol\% $\mathrm{CO}$ had two different general error trends. At $923 \mathrm{~K}$ there was an initial shift of $+7 \mathrm{~K}$ (positive error) and continuing positive error drift to $10 \mathrm{~K}$ at $2500 \mathrm{~h}$. At $1023 \mathrm{~K}$ an initial positive shift of $16 \mathrm{~K}$ occurred. Positive drift continued to a maximum of $19 \mathrm{~K}$ at $80 \mathrm{~h}$ followed by a negative drift to an error of $-50 \mathrm{~K}$ at $2500 \mathrm{~h}$. At 1023 the initial positive error shift was not observed but the error drifted negatively to about $-120 \mathrm{~K}$ at $2000 \mathrm{~h}$. A11 thermocouples were reported being extremely brittle after $2500 \mathrm{~h}$. 
Drift tests ${ }^{38}$ on Chromel-P-Alumel showed positive error drifts typical of an oxidizing atmosphere when exposed continuously to flowing helium at $1273 \mathrm{~K}$. Experiments with uncontaminated assemblies in stagnant helium atmospheres at $1273 \mathrm{~K}$ showed rapid negative error drifts followed by a drift rate of approximately $-0.6 \%$ per $h$. This trend is typical of Chromel-Alumel in a reducing atmosphere. Dull Chromel heated at $1273 \mathrm{~K}$. in stagnant helium ${ }^{38}$ quickly brightened, negative errors developed, and the magnetic attraction increased. The observation of magnetic attraction indicates significant loss of chromium solute as $\mathrm{Ni}-\mathrm{Cr}$ alloy becomes magnetic at about $7 \mathrm{wt} \% \mathrm{Cr}$ and the negative drift would be predicted from. Fig. 7d for large loss of chromium. Bright Chromel-P also developed large negative errors. 38 The helium used in these experiments was passed through a liquid nitrogen-charcoal trap and analyzed at less than 1 ppm oxygen and water. However, gas analysis during heating of the dull Chromel showed presence of $\mathrm{CO}_{2}, \mathrm{CO}, \mathrm{H}_{2}$, and a trace of $\mathrm{H}_{2} \mathrm{O}$ which may have been in part responsible for the drifts.

Pure carbon monoxide will not oxidize nickel at elevated temperatures but would readily oxidize the solutes such as chromium, aluminum, manganese, and silicon (Ref. 39, p. 349)。Carbon dioxide would be oxidizing to all elements present in Chrome1-Alumel (Ref. 39, p. 349). In C0-rich mixtures, carburization, in addition to oxidation, removes chromium.

F. Long-Term Stability

If we integrate the Seebeck coefficient changes at appropriate heat-treatment times in Fig. 4, we can construct a typical curve of maximum expected Chromel-Alumel thermocouple measurement error due to short-range ordering vs temperature as shown in Fig. 13. The standard error limits for Type $K$ thermocouples are shown for comparison. The standard error limits appear to apply to new wire, as sold, and they seem to imply very little, if anything, about accuracy after heat treatments, anneals, or a period of use. Figure 13 does not include effects of solute depletion and assumes that the material was initially in the ground state. Since short-range ordering is reversible and its degree is dependent on time, temperature, and past thermal history, the error curve represents a maximum expected error caused by short-range ordering upon initial heating. Such errors are possible since, when measuring temperatures above $523 \mathrm{~K}$, the portion of the Chromel conductor in regions where the temperature exceeds $523 \mathrm{~K}$ will have varying degrees of short-range ordering according to the temperature and 
time relationships of Fig. 4 The error in Seebeck coefficient will then vary along the affected length of conductor in the temperature gradient. The integral of the product of the coefficient change and the associated temperature gradient then provides the maximum error curve. This applies to the initial heating of undisturbed conductors in a temperature gradient. If the affected (inhomogeneous) region of the conductor and the environmental temperature profile are now moved with respect to each other, the error shown could increase or decrease, depending on the actual temperature profile and the relative direction of motion, due to the temperature dependence of short-range ordering and its reversible nature.

In addition, one might conceivably create the situation where Chromel has been made to achieve the maximum degree of short-range order (for example, by heat treatment at about $575 \mathrm{~K}$ ) and is then used to measure a temperature of $473 \mathrm{~K}$ or lower. Short-range order errors of $3 \mathrm{~K}$ could occur in this case at $473 \mathrm{~K}$. If such a treated conductor were used to measure temperatures above $575 \mathrm{~K}$, the portion of the conductor in the gradient up to $523 \mathrm{~K}$ would contribute $+3.5 \mathrm{~K}$ error and the portion in the gradient above $523 \mathrm{~K}$ would contribute additional errors as determined by the curve in Fig. 13. It is doubtful that anyone would want to actually create this postulated situation in practice; however, some reported heat treatments prior to evaluation testing have been responsible for similar errors.

To consider effects of solute depletion, curves of Seebeck coefficient changes such as those in Fig. 12 are integrated to produce temperature error vs temperature relationships as shown in Figs. 14a, b, and $c$. These figures show the errors expected for depletion of chromium in $\mathrm{Ni}-\mathrm{Cr}$ alloys of two different initial $\mathrm{Cr}$ concentrations. It is of interest to note that the error is positive over the range of temperatures and depletions considered for an alloy with 10 wt\% initial chromium content while both positive and negative errors of lesser maximum magnitude are expected when an initial $9 \mathrm{wt} \% \mathrm{Cr}$ alloy is depleted. A depletion of approximately 0.8 to $0.9 \mathrm{wt} \% \mathrm{Cr}$ in $\mathrm{Fig}$. 14a agrees well with stability data of $\mathrm{Dah}^{32}$ at $1473 \mathrm{~K}$ for $200 \mathrm{~h}$. If the solute depletion is considered to be a function of time, it is easy to visualize the time behavior of the error at a given temperature in Figs. $14 \mathrm{a}$ and $14 \mathrm{~b}$ and to see that considerably different stability test results may be expected from the two similar $\mathrm{Ni}-\mathrm{Cr}$ alloys. 
Figure $14 \mathrm{c}$ shows expected errors derived from $\mathrm{Fig}$. 12b with arbitrary solute depletions in both the $\mathrm{Ni}-\mathrm{Cr}$ and $\mathrm{Ni}-\mathrm{Al}$ alloys. The general shape of this errortemperature relationship agrees well with data in Ref. 32, particularly below $1073 \mathrm{~K}$. The Alumel error curve in Fig. 14c compares closely to errors reported in the above reference for 8-gauge conductors, $50 \mathrm{~h}$ at $1473 \mathrm{~K}, 400 \mathrm{~h}$ at $1363 \mathrm{~K}$, and $1000+h$ at $1253 . K$.

While no quantitative data have been found, it is believed also that the Seebeck coefficient variations with time and temperature, shown in Fig. 4 for $90 \mathrm{Ni}-10 \mathrm{Cr}$ alloys, are a function of the chromium content. Nickel alloys of about 14 to $15 . \mathrm{wt} \% \mathrm{Cr}$ are believed to not exhibit these coefficient changes while $20 \mathrm{wt} \% \mathrm{Cr}$ alloy exhibits a short-range order Seebeck coefficient error opposite in sign to that for $10 \mathrm{wt} \% \mathrm{Cr}$ a $110 y .10$

Based on this analysis of error behavior with solute depletion, it is believed that some differences between reported Chromel-Alumel stability test results may be attributed to differences in initial conductor solute contents. These considerations also indicate that more basic information, similar to that in Fig. 4, on changes in Seebeck coefficient with temperature, time, and environmental paramenters is needed for known conductor compositions.

Figure 15 presents error-temperature curves derived for short-range ordering in Chrome1, for several solute depletions, and for nuclear transmutations in both alloys. Only short-range ordering and transmutation relationships have been related to exposure time in the disturbing environment; it is doubtful that solute depletions can be similarly related to exposure time. In general, we would expect errors to be initially positive because of the predominance of the short-range ordering effects. As the solutes are chemically attacked by the environment or by impurities in the assembly, the errors could be of either sign depending upon initial solute content and which solute or oxide is altered. In a freely oxidizing environment, the errors in this phase would normally drift positively along with those due to the short-range ordering effect. In a reducing atmosphere they would drift negatively, perhaps rapidly. As the nuclear transmutations increase, the drift would be negative. The graph shows that the transmutation of manganese makes the principal contribution to the negative error produced by thermal neutron irradiation. 


\section{G. Insulation and Sheath}

It was the original intent of this study to also address insulators, sheaths, and swaged assemblies, among other concerns, for in-reactor use; however, termination of the task made it desirable that we try to conclude a portion of the study in a meaningful way rather than address a 11 identified concerns superficially. We mention several concerns briefly.

The insulation must be compatible with the conductor and sheath materials over the time-temperature intervals of interest. Some refractory oxides are responsible for releasing oxygen in the assembly. The degree of insulator compaction is important as this has been related to thermocouple failure. 40,41 The purity of the insulation is very important and there have been questions in the past regarding the control and measurement of the impurity contents to desired levels of precision.

Several models have been proposed (Refs. 27, p. 53; 29, pp. 21.1, 35.1, 31.1; $42 ; 43 ; 44 ; 45 ; 46$ ) for predicting thermocouple errors caused by insulator shunting of the generated emf, particularly at high temperatures. These models have not been reviewed; however, all depend on knowledge of the insulation physical and electrical properties in the environment. Published data on these properties do not indicate that a great deal of confidence should be placed in their use. Considering the variability of thermocouple test data, for cases not involving insulation, it is difficult to imagine how these models can be verified or justified. Fortunately, this problem is believed to be of interest. above 1600 to $1800 \mathrm{~K}$, which is above the useful range of Chromel-Alumel.

Radiation-induced variations, however, are of interest particularly for their effect on the observed emf when a thermocouple conductor fails jas an open circuit in a reactor environment. Reference 35 is suggested for a review of thermal-and radiation-induced changes in refractory oxides and for an analysis of the effects of conductor open-circuit failures.

The integrity of the sheath throughout the lifetime of the assembly is very important. Sheath materials, particularly 50Mo-50Re, did not hold up well in tests at 1033 to $1255 \mathrm{~K}$ in $\mathrm{C}, \mathrm{C}-\mathrm{Si}, \mathrm{He}, \mathrm{H}_{2}$, and $\mathrm{CO}$ atmospheres. ${ }^{37}$ Niobium sheathing must be avoided in the HTGR gas environment as this material is believed to be subject to strong gas-phase corrosion. 35

In some environments, austenitic stainless steels have a tendency to form pits. While their depth may normally be relatively shallow, tolerance against sheath penetration is needed. Susceptibility to pitting varies with surface 
condition, 47 the smoother the surface the better the resistance. Tantalumsheathed, Be0-insulated, W-Re thermocouples have exhibited high failure rate and decalibration when the Ta sheath contacted graphite (Ref. 29, p. 27.1).

VI. IN SITU CALIBRATION

Figure 16a illustrates a hypothetical case where irradiation induced changes in composition are impressed on thermocouple conductors in an assumed temperature profile and an in situ calibration temperature profile is applied to the conductors while they are in service. It is assumed that the conductors have emf characteristics similar to those illustrated in Figs. Tb and 14a, $\mathrm{T}_{0}=1273 \mathrm{~K}, \mathrm{~T}_{\mathrm{Ca}}=1373 \mathrm{~K}$, and that $0.5 \%$ of the chromium has been transmuted The change, $\Delta s$, in the Seebeck coefficient will be small at $1323 \mathrm{~K}$ (Fig. 14a) but will increase at lower temperatures in the region $x_{1}-x_{2}$ of the temperature gradient. In the temperature range between $T_{0}$ and $T_{\text {cal }}, \overline{\Delta S}_{n}$ is very small compared to the variation of $\Delta s_{x_{1}} x_{2}$ in the gradient between $x_{1}$ and $x_{2}$.

If the effects are dependent only on change in composition, relative emfs as shown in Fig. 16a. would be predicted. These voltage profiles qualitatively compare the emfs generated in the inhomogeneous conductors with those in the ideal homogeneous case. The inhomogeneity in region $x_{1}-x_{2}$ would cause the observed emfs for $T_{0}$ and $T_{\mathrm{Ca}}$ to be greater than the expected readings in the ideal case. The reading of $\mathrm{T}_{\mathrm{cal}}$, in the assumed profiles, would contain an additional, very small positive error due to small $\overline{\Delta s}$ (or integral of $\Delta s(T)$ ) over the region of the calibration temperature gradient. This postulated in situ calibration would provide a good estimate of the maximum error at $1373 \mathrm{~K}$ for chromium depletions of $0.5 \%$ or less. Calibration at other temperatures would contain larger contributions to $\Delta s$ from inhomogeneities in the calibration temperature gradient; however, the overall error at the calibration temperature would be determined properly under the assumed conditions.

It is of interest to note in Fig. 14a, derived from Fig. $7 b$ for a typical nickel alloy with an initial chromium content of $9 \%$, that reductions of chromium content to $8.5 \%$ could produce errors of $+5.4 \mathrm{~K}$ between 1273 and $1373 \mathrm{~K}$ while exhibiting smaller errors above and below this range if calibrated by conventional techniques. This illustrates the need for improved methods of investigation and calibration technique and also shows that use of a single calibration temperature to assess in-service calibration error and the effects of environmental testing may produce fortuitously good or bad results. 
Figure 16b illustrates another hypothetical case, which may be representative of conditions prevailing during a reported ${ }^{48}$ in situ, in-pile calibration. No temperature or neutron flux profile data along the conductors were given in the report; however, from the description of the test rig, it is possible that the flux-affected regions of the conductors were at approximately isothermal conditions during calibration. Any emf error observed during calibration will relate only to possible departure from isothermal conditions in region $0-x_{1}$ and inhomogeneities in region $x_{1}-x_{2}$, which was not altered by the neutron flux. Thus it is possible that effects other than irradiation-induced inhomogeneities were measured. The results of these calibrations, as shown in Fig. 16b, apply only to the detailed conditions under which they were obtained. Reporting of the irradiation temperature and differential emf observed between this temperature and the calibration temperature, though not as accurate as the calibration point information, would have been very informative.

\section{EXPERIMENTAL DATA}

Documentation of experience, in varying detai1, with over 1500 ChromelAlumel thermocouples of various designs in a variety of environments has been reviewed. A portion of this information is presented in the following sections.

\section{A. Bare Elements}

Some published data for maximum observed errors in bare Chromel-Alumel thermocouples operating in a freely oxidizing environment are presented in Fig. 17. These data cover 1000 to $18000 \mathrm{~h}$ of operation, as indicated in the figure, and as a result they do not directly correlate for temperature-time error dependencies as plotted. In addition, this simple summary cannot convey all of the pertinent details such as heat treatments, thermal cycling, and other differences which have important bearing on the observed errors and their interpretation. Also the methods used to arrive at most, but not a11, ${ }^{32}$ of the plotted errors are subject to some question. The observed errors in the range 523 to $923 \mathrm{~K}$ are within the maximum expected error for the short-range ordering inhomogeneity calculated from Fig. 4. Negative errors at 573 and $663 \mathrm{~K}$ are not confidently predicted by any mechanisms in a freely oxidizing atmosphere covered in this study. Errors above $1073 \mathrm{~K}$ could correlate with oxidation or various solute depletions; however, we have no data on which to base such comparisons.

The data in Fig. 4 and the model were used to calculate errors introduced by $673 \mathrm{~K}$ heat treatments reported in Ref. $27, \mathrm{p} .14$. Agreement was good as shown in Table II. 
TABLE II

ERRORS INTRODUCED BY HEAT TREATMENTS

TEMPERATURE

ERROR

MEASURED CALCULATED

H. T. 30 min at $673 \mathrm{~K}$

$673 \mathrm{~K}$

$+1.75 K \quad+1.2 \pm 0.5 k$

$693 \mathrm{~K}$

$+1.88 K+1.4 \pm 0.5 K$

H. T. $4 \mathrm{~h}$ at $673 \mathrm{~K}$

$505 \mathrm{~K}$

$+3.2 k+2.5 \pm 0.5 k$

$693 K$

$+4.4 K \quad+4.6 \pm 0.5 K$

Figure 4 and the model were also used to calculate errors for comparison with measured errors reported in Refs. 49 and 50. Similarly good agreement was obtained.

B. Sheathed Elements

Some published data for maximum observed errors in sheathed Chromel-Alumel thermocouples are plotted in Fig. 18. These data cover 2000 to $18000 \mathrm{~h}$ of operation and to the extent that time and temperature produce drifts, direct correlations between results are not intended. These data are presented without distinction of details such as insulation and sheath materials, wire gauge, sheath diameter, or fabrication procedure. Comparison of these drift data with those in Fig. 17 indicates no significant differences in stability. If anything, the sheathed units may be slightly less stable. One significant point appears in this figure; the thermocouples developed and tested at CANEL ${ }^{51}$ possess a stability for $10000 \mathrm{~h}$ at $1353 \mathrm{~K}$ that is superior to other assemblies tested at lower temperatures. Rigorous quality control on all components and steps of the assembly is believed to have resulted in thermocouple performance that is independent of the environment - oxidizing or reducing, pressure or vacuum limited only by the permeability of the sheath and end seals. Other efforts to control materials and assembly (Refs. 27, p. 95; 29, p. 27.1; 52, p. 551) have experienced some difficulty and the degree of success with subsequent work is not known.

The following metallurgical changes are postulated as a possible explanation of causes and effects that could produce reported error-time trends of sheathed Chromel-Alumel thermocouples. During prolonged exposures at 1073 to $1273 \mathrm{~K}$, 
among other changes, precipitates of oxides of the solutes appear in the depleted alloy matrix. In early stages of these changes, formation of an alloy of aluminum, probably $\mathrm{Al}_{2} \mathrm{O}_{3}$, has been found ${ }^{15}$ in the Chromel conductor that normally does not contain aluminum. Oxides of chromium appear in later stages. Oxides of aluminum, manganese, and silicon appear, presumably at a later stage, at the grain boundaries in the Alumel conductor. Figure 9 and Ref. 39, p 349, show that at high temperatures and sufficiently. low partial pressures of oxygen, aluminum would be preferentially oxidized. At a given temperature, increasing partial pressure of oxygen would subsequently selectively oxidize the manganese and silicon in the Alumel conductor. This would be expected to reduce the emf error produced by the aluminum removal. Additional increase in oxygen partial pressure would result in oxidation of chromium in the Chromel. This would normally initially contribute to increased error in a positive direction in the 1073 to $1273 \mathrm{~K}$ range but would be expected to change to a negative error contribution (Fig. 14a) if the depletion continued. This reasoning suggests that sealed, sheathed assemblies might be expected to exhibit positive emf errors early in life at high temperatures if care were taken to reduce, but not eliminate, the free oxygen inside the assemblies. Errors from short-range ordering would also be positive and are presumed to add to errors produced by the initial solute depletions. Long term drift of increasing negative errors would be expected to follow the initial positive errors. Figure 19 shows calculated error-temperature characteristics for three values of aluminum depletion and for three values of chromium depletion accompanied by a fixed depletion of aluminum. A limited amount of dissolution in the Chromel-Alumel wires at the hot junction was believed to have occurred during $10000-h$ tests at $1373 \mathrm{~K}^{51}$ Data $^{36}$ on 97 assemblies show that the drift in all cases is in the direction of increasing negative errors with time. Detail in this data does not appear to show appreciable initial positive error drift as suggested by the above reasoning.

C. Combined Disturbing Effects Including Irradiation

We would expect the effects of irradiation to combine with the effects of oxidation, impurities, contamination, etc., in producing emf-temperature errors. While we have no real insight into this from the published data, we might make some judgment, based on transmutation predictions and solute depletion by oxidation, as to expected error trends under these combined conditions. Alteration of the chromium and aluminum content would initially cause positive errors 
increasing in magnitude with temperature. Alteration of silicon and iron content would tend to be compensating while expected changes in manganese would combine to produce large negative errors. On this basis it is expected that initial error drifts would be positive at all temperatures followed by decreasing error magnitudes at high temperatures and finally errors would become negative, particularly at high temperatures and long exposure times. Some published test data for measured errors in irradiated Chromel-Alumel thermocouples are shown for comparison in Fig. 20. None of the information assembled for this figure provides insight into drift trends with time and only one reference 53 provided experimental data which might permit separation of irradiation effects from those of other factors. The errors shown for irradiated units do not differ significantly from those in Fig. 18 for unirradiated, sheathed assemblies. The methods used to arrive at most of the reported errors. in Fig. 20 are subject to considerable question. Separation of effects would be important for the analysis, understanding, and implementation of effort to improve the performance of these devices.

VIII. SUMMARY AND CONCLUSIONS

Instabilities in thermocouples cannot be related quantitatively to their causes by classical theory and conventional calibration techniques since both assume that the conductors are ideally homogeneous. Thermocouple conductors are routinely produced in an essentially homogeneous condition; however, all types develop inhomogeneities to some extent during use. A model of the inhomogeneous thermocouple and an empirical method for determining inhomogeneity in the Seebeck coefficient were presented. The role of temperature gradient in the generation of thermoelectric emf and temperature errors was stressed. The inappropriateness of post-service or post-test use of conventional calibration technique to determine in-service errors was discussed; much of the reported error data have been generated by this method.

Factors which cause the relative Seebeck coefficients to vary (inhomogeneity) and which affect long-term performance were delineated. Bases for the general belief that thermocouples are little affected by irradiation and that Chrome1-Alumel thermocouples have performed satisfactorily were sought, but not found. If these beliefs are based on sound experimental evidence, our understanding of the decalibration mechanism may be incomplete. 
In the investigation of irradiation effects it would seem that a prerequisite should be to achieve thermocouple designs with consistent and acceptable stability and reliability when exposed to environmental factors (other than irradiation) for extended periods of time. The dependence of the Seebeck coefficient errors with environment, temperature, and time should be determined for such designs. Then the effect of irradiation on error in Seebeck coefficients should be determined and presented in a manner permitting meaningful correlation with neutron fluences and temperature. These designs and error data could then be used for a broad spectrum of applications. The in situ, in-pile calibrations done todate are believed to be the best information available provided these were conducted in a manner that assured application of the calibration temperature gradient to the conductor region affected by a known neutron fluence. This approach has the disadvantage of very 1 imited information yield per test. It is believed that the scanning gradient method can be of significant value in maximizing the meaningful data obtained from thermocouple testing, particularly from irradiation effects testing.

Although insulation and sheath problems were not included in this study, the presence of oxygen, impurities, and contaminants in the assembly is of concern. We have considered the effects of several elements on the conductors and the emftemperature characteristics; these and other elements expected to be present in the HTGR coolant must be kept out of the assembly if the thermocouples are to have good long-term stability and reliability. In particular, impurities and contaminants whose transmutation by-products are degrading to thermocouple performance must be eliminated inside the assembly. Organic matter can form carbon that can lead to a reduction reaction and traces of moisture may enhance radiation effects. The sub-stoichiometric character of some refractory oxides, such as $\mathrm{BeO}$ and $\mathrm{MgO}$, is responsible for the presence of free oxygen atoms and fast neutron bombardment can also free oxygen atoms inside the assembly. Embrittlement caused by fast neutron bombardment could produce common mode failures.

Even though there exists significant disparity among published results from studies in the temperature region above $1148 \mathrm{~K}$ and possibly a diversity of opinions supporting the authenticity of such results, it is believed that sufficient insight may exist to permit the construction and successful use of Chromel-Alumel thermocouples above $1123 \mathrm{~K}$ for extended periods of time with acceptable confidence in measurement error limits. Confirmatory studies, however, may be needed to 
verify the one previous thermocouple design that performed satisfactorily above $1123 \mathrm{~K}$.

If acceptable error limits are not attainable with present knowledge, more basic work will have to be performed to isolate conditions and effects and to identify those parameters that must be more closely controlled in order to achieve acceptable performance. An alternative to this is to select other alloys that are environmentally and thermoelectrically stable in the application. This, however, may also involve work to isolate detailed conditions and effects in order to successfully apply the alternative alloys and to assure that long-term stability can be achieved. Users may also have to accept thermocouples that do not conform to currently accepted standard calibrations. 


\section{REFERENCES}

1. W. F. Roeser, "Temperature, Its Measurement and Control in Science and Industry," (Reinhold Publishing Corporation, New York, 1941), pp. 180205.

2. A. Somerfeld, "Thermodynamics and Statistical Mechanics," (Academic Press, Inc., New York, 1956), pp. 156-163 and 342.

3. F. Seitz, "The Modern Theory of Solids," (McGraw-Hill Book Company Inc., New York and London, 1940), pp. 178-181.

4. R. J. Moffat, "Temperature, Its Measurement and Control in Science and Industry," (Reinhold Publishing Corp., New York, 1962), Vol. 3, Part 2, p. 33-38.

5. W. F. Roeser and H. T. Wensel, "Temperature, Its Measurement and Control in Science and Industry," (Reinhold Publishing Corp., New York, 1941), pp. 284-314.

6. A. W. Fenton, "Temperature, Its Measurement and Control in Science and Industry," (Instrument Society of America, Pittsburgh, 1971), Vol. 4, Part 3, pp. 1973-1990.

7. K. R. Carr, "Temperature, Its Measurement and Control in Science and Industry," (Instrument Society of America, Pittsburgh, 1971), Vol. 4, Part 3, pp. 1855-1866.

8. R. Nordheim and N. J. Grant, "Resistivity Anomalies in the NickelChromium System as Evidence of Ordering Reactions," Journal of the Institute of Metals, Vol. 82, pp. 440-444, (1953-1954).

9. Von U1rich Dehlinger, "Der Widerstandsverlauf in Mischkristallen mit Nahordnung," Z. Meta11k., Vol. 53, pp. 577-579, (1962).

10. N. A. Burley, "Temperature, Its Measurement and Control in Science and Industry," (Instrument Society of America, Pittsburgh, 1971), Vol. 4, Part 3, pp. 1677-1695.

11. V. A. Calcut, "Aging of Chromel-Alumel Thermocouples," United Kingdom Atomic Energy Authority report, UKAEA TRG report 1021 (R/X), (1965).

12. N. A. Burley, "Short-term, Reversible Emf Drifts in Nickel-Base Thermocouple Alloys," Australian Defence Scientific Service, Defence Standards Laboratories report $353,(1970)$.

13. M. W. Thomas and K.E.G. Meredith, "The Embrittlement of Nickel Base Alloys Containing Aluminum and Chromium as Used for Thermocouple Materials," British Corrosion Journa1, Vol. 1, pp. 199-204, (March, 1966).

14. P. C. Hughes and N. A. Burley, "Metallurgical Factors Affecting Stability of Nickel-Base Thermocouples," Journal of the Instftute of Metals, Vol. 91, pp. 373-376, (1962-63). 
15. N. A. Burley, "Solute Depletion and Thermo-E.M.F. Drift in Nickel-Base Thermocouple Alloys," Journal of the Institute of Metals, Vol. 97, pp. 252-254, (1969).

15. E. D. Zysk and A. R. Robertson, "Temperature, Its Measurement and Control in Science and Industry," (Instrument Society of America, Pittsburgh, 1971), Vol. 4, Part 3, pp. 1697-1734.

17. N. F. Spooner and J. M. Thomas, "Longer Life for Chromel-Alumel Thermocouples," Metal Progress, Vol. 68, No. 5, pp. 81-85, (Nov., 1955).

18. W. I. Pumphrey, "The Embrittlement of Chromel and Alumel Thermocouple Wires," Journal of the Iron and Steel Institute, Vol. 157, pp. 513-516, (Dec., 1947).

19. A. G. Hotchkiss and H. M. Webber, Protective Atmospheres, (John Wiley and Sons, Inc., New York, 1953).

20. W. E. Browning, Jr. and C. E. Miller, Jr., "Temperature, Its Measurements and Control in Science and Industry," (Reinhold Publishing Corp., New York, 1962), Vol. 3, Part 2, pp. 271-276.

21. T. P. Wang, C. D. Starr, and N. Brown, "Thermoelectric Characteristics of Binary Alloys of Nickel," Acta Metallurgica, Vol. 14, pp. 649-657, (May 1966).

22. Von W. Rohn, "Thermoelektrische Untersuchungen an Nickel legierungen," Zeitschrift für Metallkunde, Vol. 16, pp. 297-300, (August 1924).

23. J. F. Potts, Jr., and D. L. McElroy, "Thermocouple Research to 1000 C Final Report, November 1, 1957 through June 30, 1959," Oak Ridge Nationa1 Laboratory report, ORNL-2773 (January 23, 1961).

24. J. F. Potts, Jr., and D. L. McElroy, "Temperature, Its Measurement and Control in Science and Industry," (Reinhold Publishing Corp., New York, 1962), Vol. 3, Part 2, pp. 243-264.

25. D. D. Pollock and D. I. Finch, "Temperature, Its Measurement and Control in Science and Industry," (Reinhold Publishing Corp., New York, 1962), Vol. 3, Part 2, pp. 237-241.

26. C. D. Starr and T. P. Wang, "Effect of Oxidation on Stability of Thermocouples," Proc. ASTM, Vol. 63, pp. 1185-1194 (1963).

27. W. R. Grimes and D. R. Cuneo, "High Temperature Thermometry Seminar, Held October 1-2, 1959, at Oak Ridge National Laboratory," Oak Ridge National Laboratory report TID-7586, Part 1 (August 1960).

28. N. C. Hoitink, R. C. Weddle, and D. C. Thompson, "Effects of Fast Neutron Irradiation on the Performance Characteristics of Reactor Grade Thermocouples," Battelle Memorial Institute Pacific Northwest Laboratories report BNWL-1365 (June 1970). 
29. "High Temperature Thermometry," U.S. Atomic Energy Commission report WASH-1067 (March 1966).

30. H. E. McCoy, Jr., "Influence of $\mathrm{CO}-\mathrm{CO}_{2}$ Environments on the Calibration of Chromel-P-Alumel Thermocouples," Oak Ridge National Laboratory report ORNL-TM-481 (March 28, 1963).

31. D. L. McElroy, "Progress Report 1, Thermocouple Research Report for the Period November 1, 1956 to October 31, 1957," Oak Ridge National Laboratory report ORNL-2467 (March 5, 1958).

32. A I. Dah1, "Temperature, Its Measurement and Control in Science and Industry," (Reinhold Publishing Corporation, New York, 1941), pp. 12381266 .

33. M. B. Herskovitz, "Thermal Cycling Life Tests of Metal Sheathed Thermocouple Assemblies," Oak Ridge National Laboratory report ORNL-TM-3907 (September 1972).

34. M. J. Kelly, W. W. Johnston, and C. D. Baumann, "Temperature, Its Measurement and Control in Science and Industry," (Reinhold Publishing Corp., New York, 1962), Vol. 3, Part 2, pp. 265-269.

35. S. Tarassenko, "Radiation Induced EMF Developing in the Insulation of Metal Sheathed Mineral Insulated High Temperature Thermocouples and Its Effects on the Thermocouple Signal," Atomic Energy Estab7ishment Dragon Project report DP-Report-912 (Dragon Project use only), Winfrith, England, (January 1975).

36. "Status of Instrument Development for the SNAP-50 Reactor Test Program," Pratt and Whitney Aircraft CANEL report PWAC-473, (September 1965).

37. R. L. Bennett, H. L. Hemphil1, W. T. Rainey, Jr., and G. W. Keilholtz, "Stability of Thermoelectric Materials in an Helium-Graphite Environment," Oak Ridge National Laboratory report ORNL-TM-746 (January 10, 1964).

38. R. L. Bennett, W. T. Rainey, Jr., and W. M. McClain, "Temperature, Its Measurement and Control in Science and Industry," (Reinhold Publishing Corp, New York, 1962), Vol. 3, Part 2, pp. 289-294.

39. L. S. Darken and R. W. Gurry, Physical Chemistry of Metals (McGraw-Hill Book Co., Inc., New York, 1953).

40. J. E. Kinzer, "International Symposium on Developments in Irradiation Capsule Technology," U.S. A.E.C. report CONF-660511, (March 1967), pp. 3.8.1-3.8.17.

41. William L. R. Rice, "Symposium on Problems in Irradiation Capsule Experiments, October 8-10, 1963," U.S. A.E.C. report TID-7697 (March 1964) pp. 4.3.1. 
42. R. L. Shepard, R. F. Hyland, J. M. Googe, and J. R. McDearman, "Temperature, Its Measurement and Control in Science and Industry," (Instrument Society of America, Pittsburgh, 1971), Vol. 4, Part 3, pp. 1841-1853.

43. William E. Bostwick, "Temperature, Its Measurement and Control in Science and Industry," (Reinhold Publishing Corp., New York, 1962), Vol. 3, Part 2, pp. 221-228.

44. G. K. Moeller, B. R. Bronfin, and P. W. Whitmarsh, "Error Determination in High Temperature Thermocouple Measurements," Institutt for Atomenergi report KT-552, Kjeller, Norway, (November 30, 1960).

45. G. Collier, "Thermocouple Program to Investigate Relative Error," Westinghouse Electric Corp., Astro-nuclear Laboratory report WANL-TME-948 (September 15, 1964).

46. G. F. Popper and A. E. Knox, "FARET In-core Instrument Development," Argonne National Laboratory report ANL-7161 (July 1966), p. 14.

47. Bjarne Aarset and Gudolf Kjaerheim, "Temperature, Its Measurement and Control in Science and Industry," (Instrument Society of America, Pittsburgh, 1971), Vol. 4, Part 3, pp. 1889-1902.

48. F. D. Carpenter, N. L. Sandefur, R. J. Grenda, and J. S. Steibe 1, "Temperature, Its Measurement and Control in Science and Industry," (Instrument Society of America, Pittsburgh, 1971), Vo1. 4, Part 3, pp. 1927-1934.

49. S. J. Green and T. W. Hunt, "Temperature, Its Measurement and Control in Science and Industry," (Reinhold Publishing Corp., New York, 1962), Vol. 3, Part 2, pp. 695-722.

50. R. A. Evans and J. Holt, "Calibration Drift Effects in Nickel-Alloy Thermocouples," United Kingdom Atomic Energy Authority Reactor Group report TRG-Report-1510 (R), Risley, England, (1967).

51. Salvatore Fanciul10, "Drift and Endurance Testing of Chromel-Alumel, $W-5 R e / W-26 R e$ and Mo/W-26Re Thermocouples at 1950F to 2000F for 10000 Hours," Pratt and Whitney Aircraft CANEL report PWAG-454, (February 23, 1965).

52. "National Symposium on Developments in Irradiation Testing Technology," U.S. Atomic Energy Commission report CONF-690910, (1969).

53. P. E. Madsen, "The Calibration of Thermocouples under Irradiation in B. E. P. 0." Atomic Energy Research Establishment report AERE M/R 649, Harwe 11, Berks, England, (January 1951).

54. M. A. Hunter and A. Jones, "Temperature, Its Measurement and Control in Science and Industry," (Reinhold Publishing Corp., New York, 1941), pp. $1227-1231$. 
55. C. Boorman, "The Effect of Neutron Flux on the Thermoelectric Power of Thermocouples and on the Resistivity of Platinum and Nickel," Atomic Energy Research Establisnment report AERE E/R 572, Harwe11, Berks, England, (September 1950).

56. G. F. Levy, R. R. Fouse, and R. Sherwin, "Temperature, Its Measurement and Control in Science and Industry," (Reinhold Publishing Corp., New York, 1962), Vol. 3, Part 2, pp. 277-282.

57. S. J. Green and T. W. Hunt, ibid, pp. 695-722.

58. N. L. Sandefur, J. S. Steibel, and R. J. Grenda, "EMF Drift of Chromel/ Alumel and $W-3 \%$ Re/W-25\% Re Thermocouples Measured In-pile to High Neutron Exposures," Gulf General Atomic report Gulf-GA-A12501, (May 24, 1973).

59. J. 0. Barner, "Evaluation of an Irradiation Environment on the Stability of Chromel-Alumel Thermocouples," General Dynamics Corporation, General Atomic Division report GAMD-3839, (November 14, 1963).

60. C. D. Martin and C. H. Gabbard, "Temperature, Its Measurement and Control in Science and Industry," (Instrument Society of America, Pittsburgh, 1971), Vo1. 4, Part 3, pp. 1869-1874. 


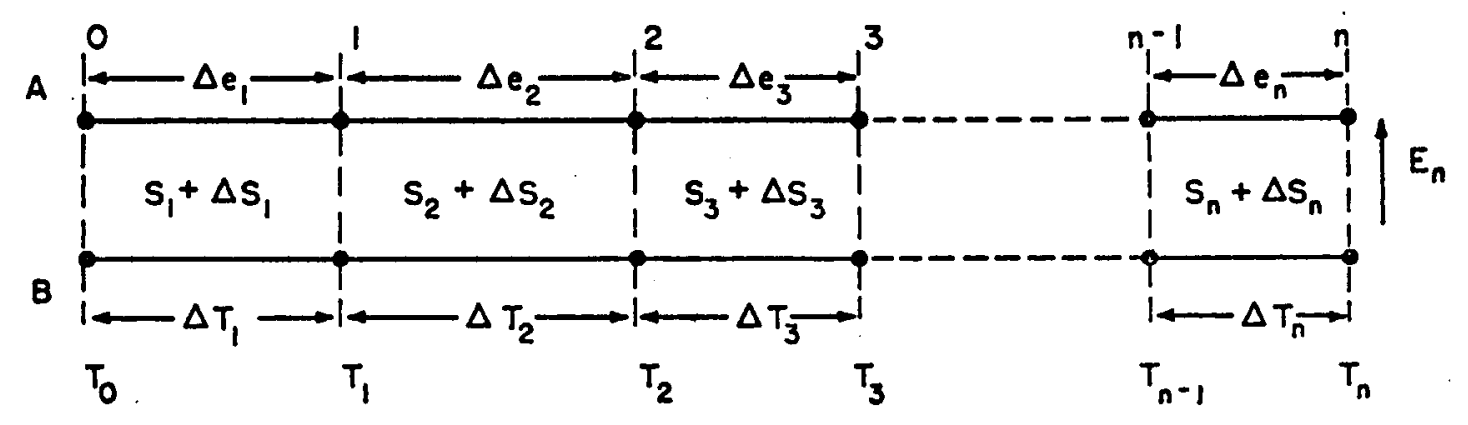

Fig. 1. Circuit model.

Conductors $A$ and $B$ are paralle 1 to temperature gradient

Nodes $0,1,2--n$ of the two conductors lie on isothermal lines, $T_{n}$ $S_{n}=$ relative Seebeck coefficient for ideal homogeneous conductors or nominal values from tables as applicable to section $n$ $\Delta S_{n}=$ deviation, in section $n$, of the actual Seebeck coefficient, $S$, from the ideal or nominal value, $S_{n}$
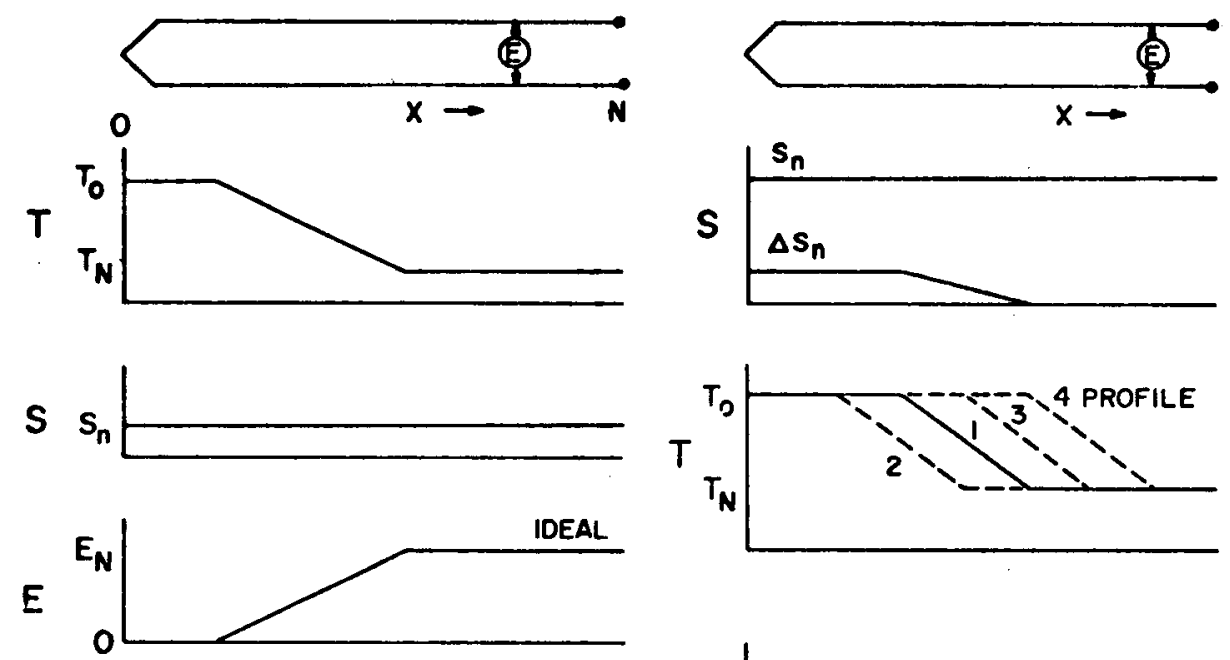

A) HOMOGENEOUS CONDUCTORS
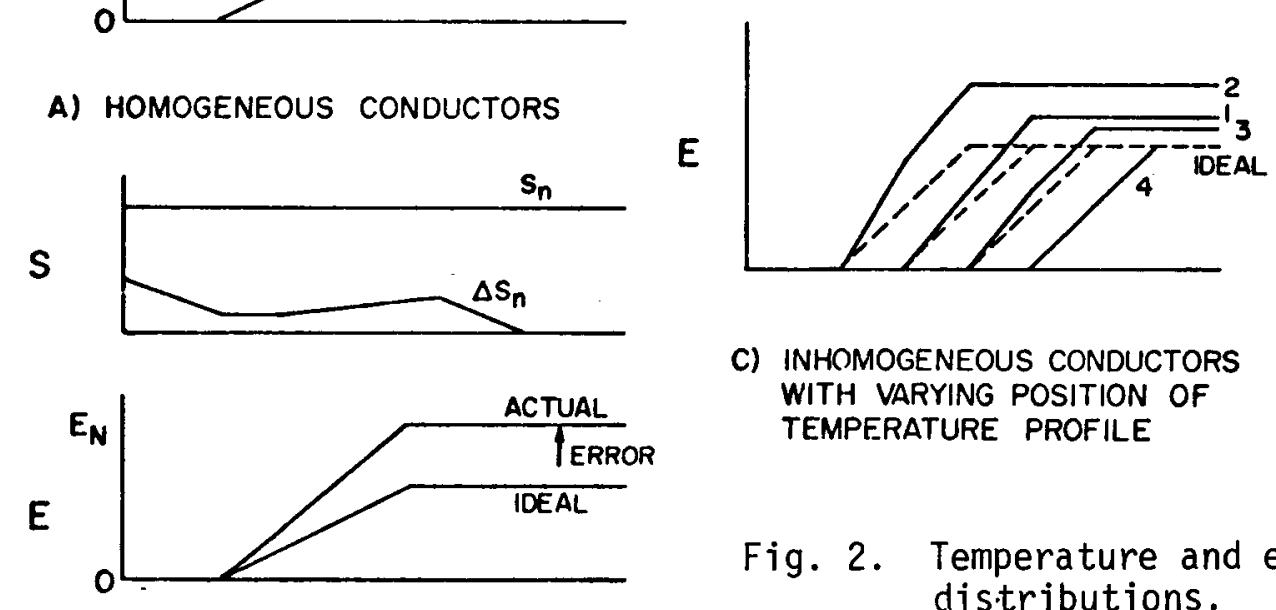
C) INHOMOGENEOUS CONDUCTORS WITH VARYING POSITION OF TEMPERATURE PROFILE

Fig. 2. Temperature and emf dis.tributions.
B) INHOMOGENEOUS CONDUCTORS - (SAME TEMPERATURE PROFILE AS A) ABOVE)




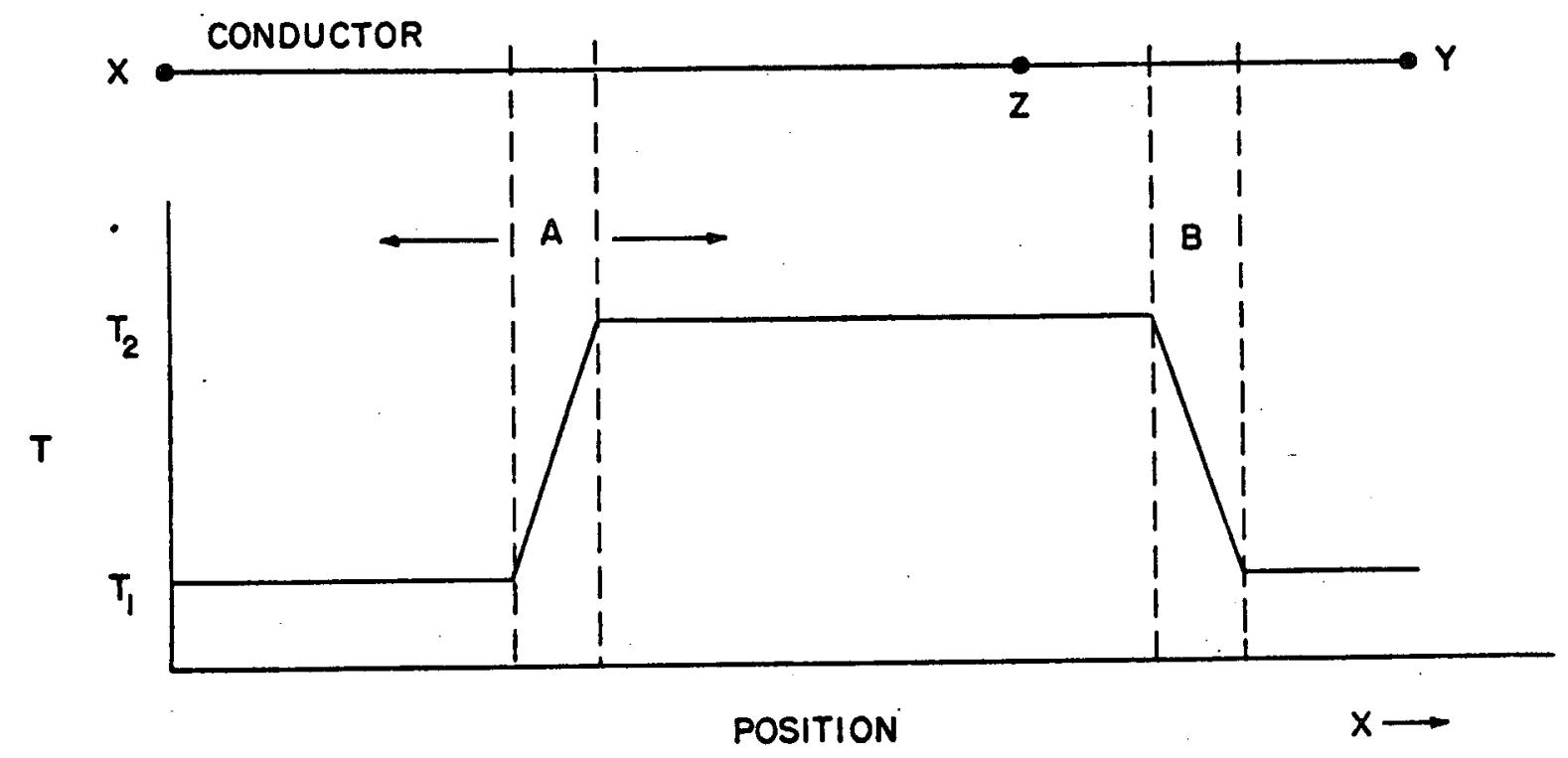

Fig. 3. Scanning gradient.

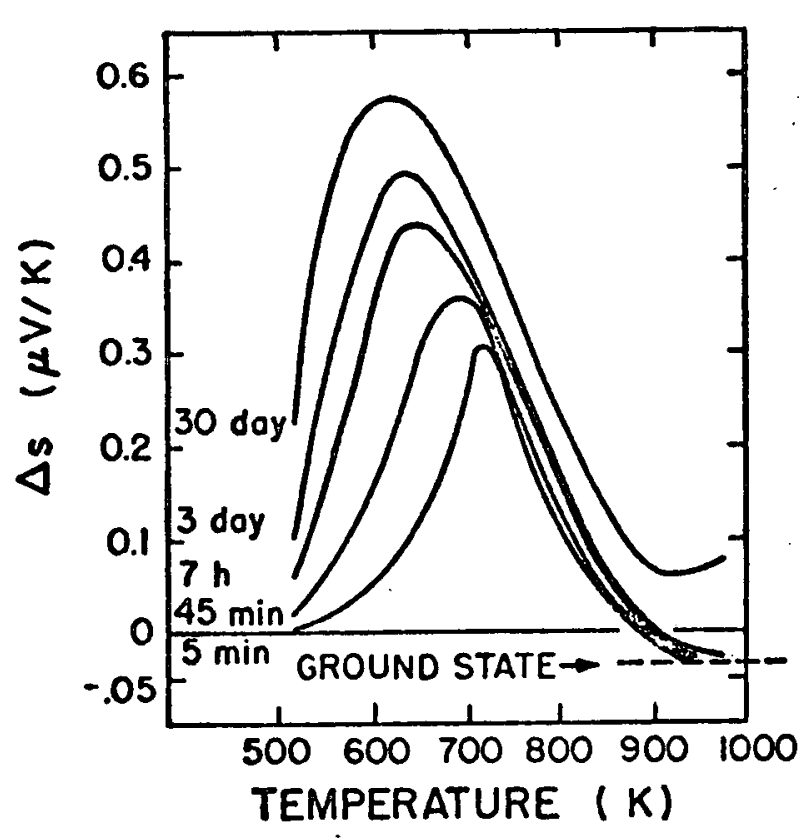

Fig. 4. Cumulative heat treatment, typical 90Ni-10Cr alloys (Ref. 6).

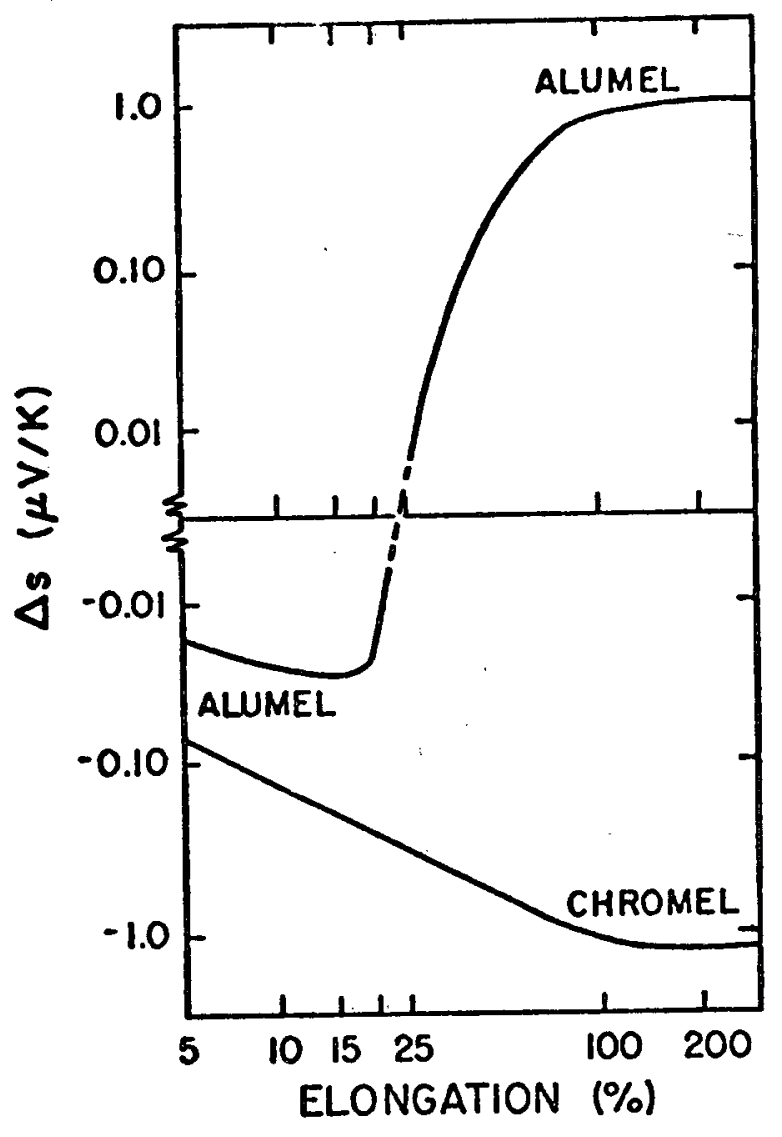

Fig. 5. Effects of cold work (Ref. 6). 


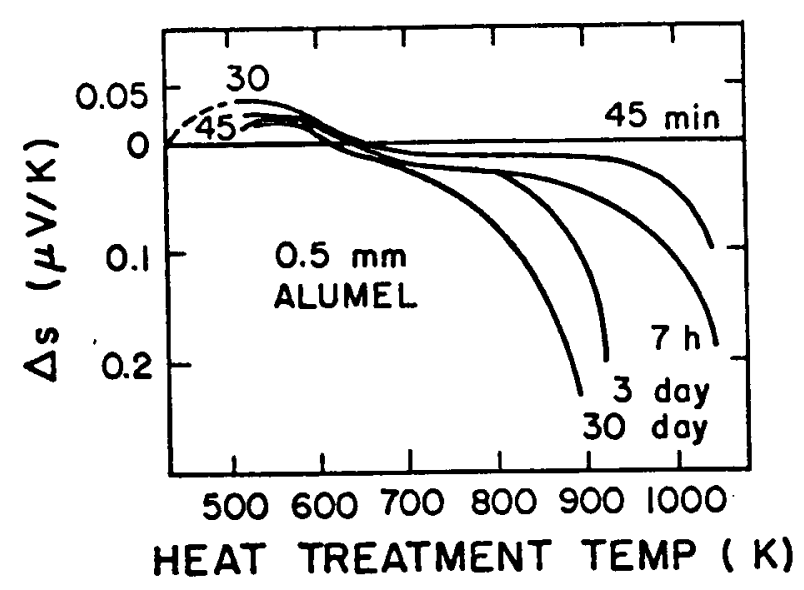

Fig. 6. Heat treatment of bare Alumel in air (Ref. 6).

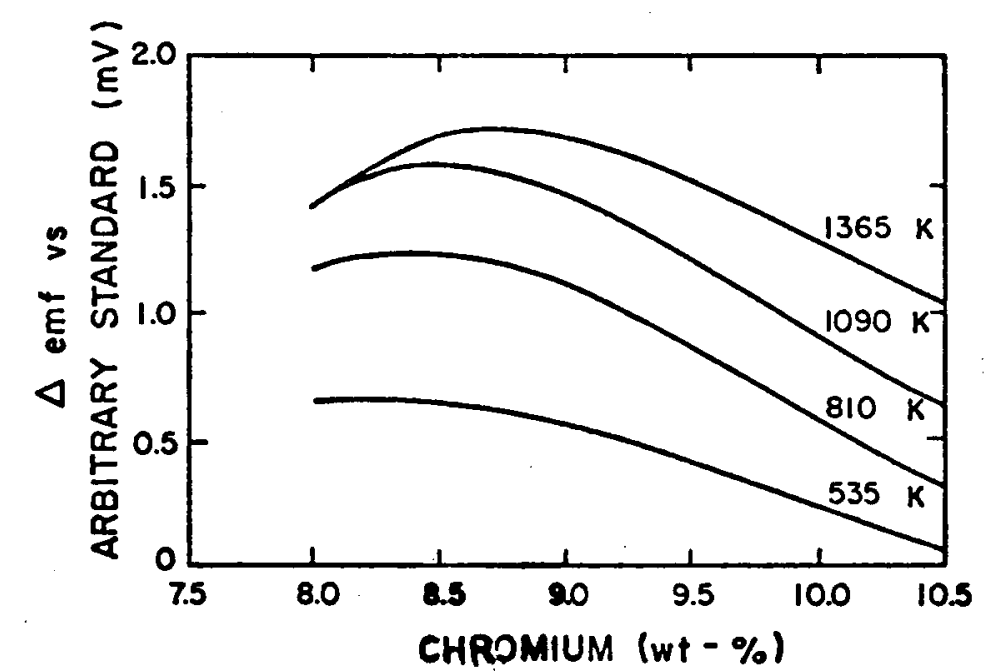

Fig. 7b. Effect of $\mathrm{Cr}$ in a Ni-Cr alloy (Tophel) on the thermo-emf (Ref. 26).

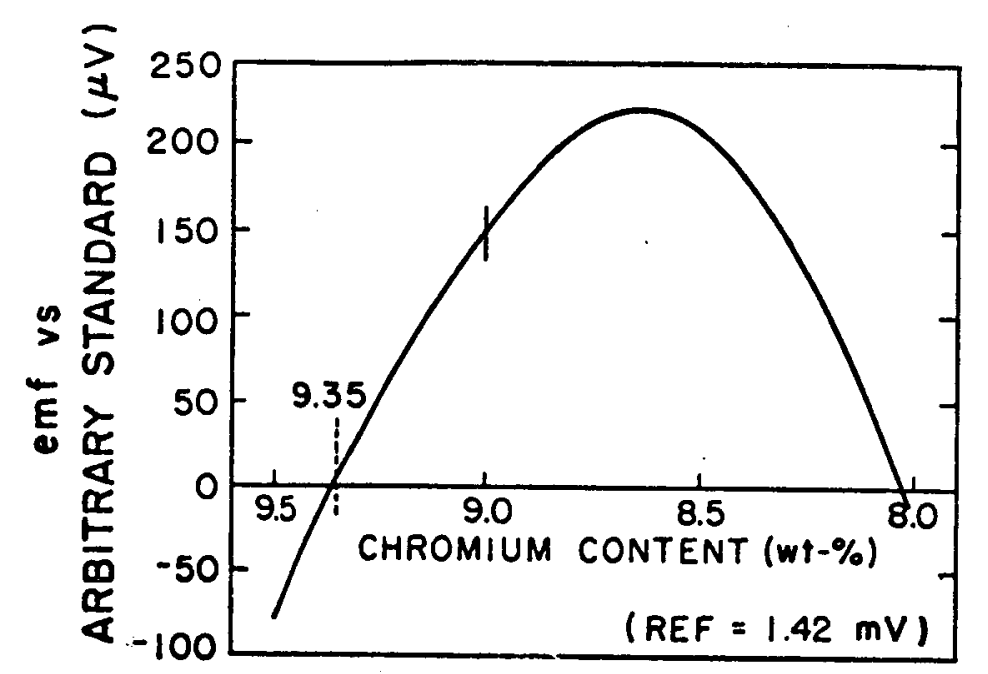

Fig. 7a. Effect of chromiun in Ni-Cr alloy on the deviation of thermo-emf from an arbitrary standard at $1273 \mathrm{~K}$ (Ref. 15).

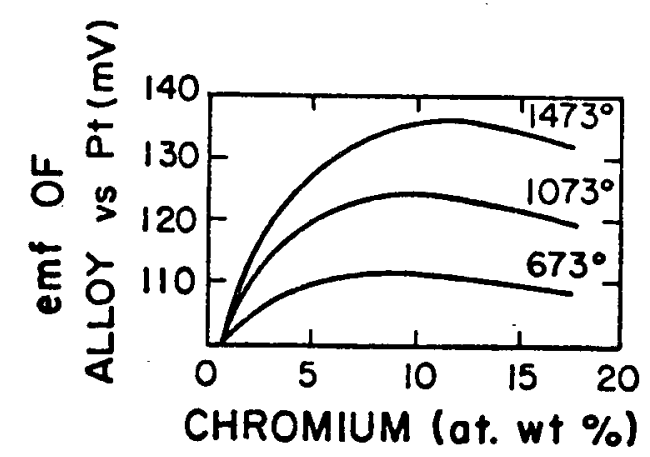

Fig. 7c. Effect of $\mathrm{Cr}$ content on thermo-emf of $\mathrm{Ni}-\mathrm{Cr}$ alloy vs Pt (Ref. 22). 


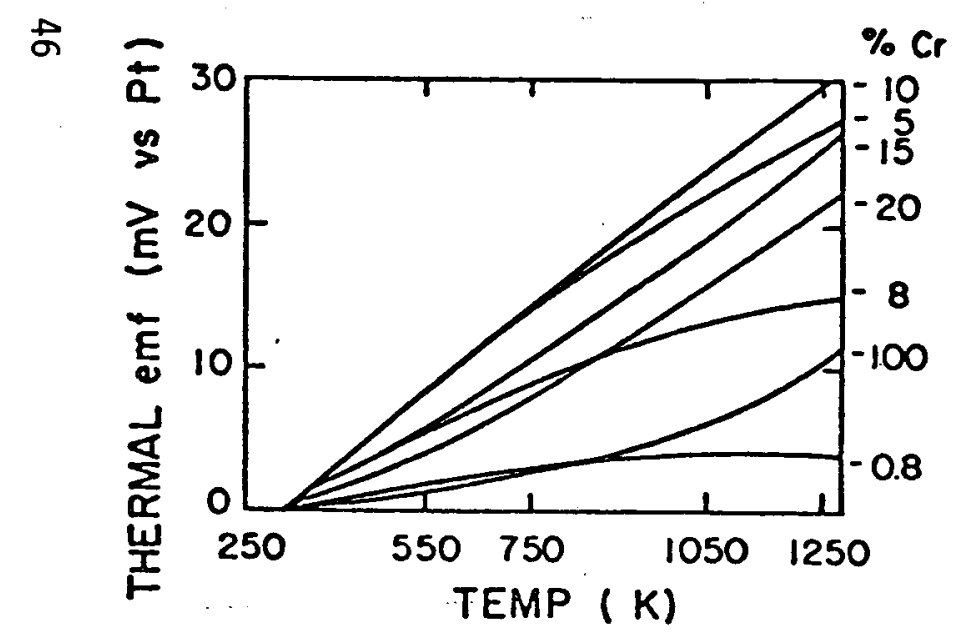

Fig. 7d. Effect of $\mathrm{Cr}$ content on thermoemf of $\mathrm{Ni}-\mathrm{Cr}$ alloys vs $\mathrm{Pt}$ (Ref. 54).

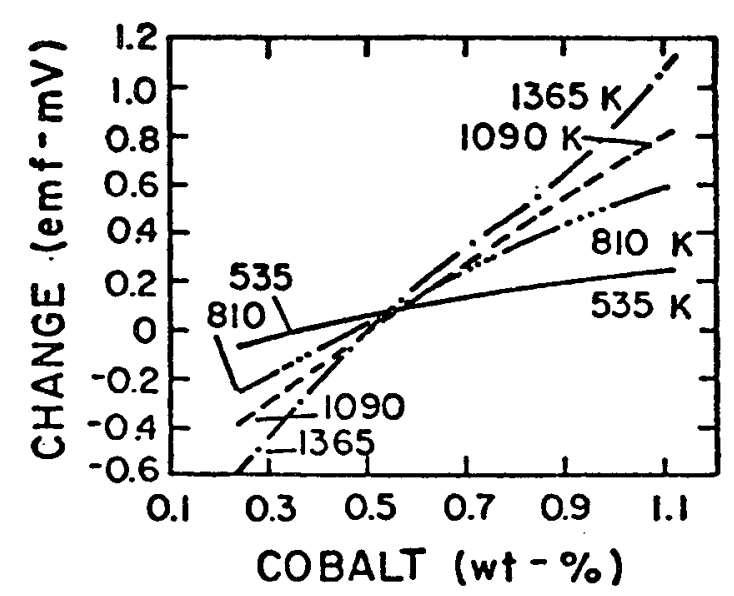

Fig. 7f. Effect of Co on the emf change of Ni-Al alloy (Nial) (Ref. 26).

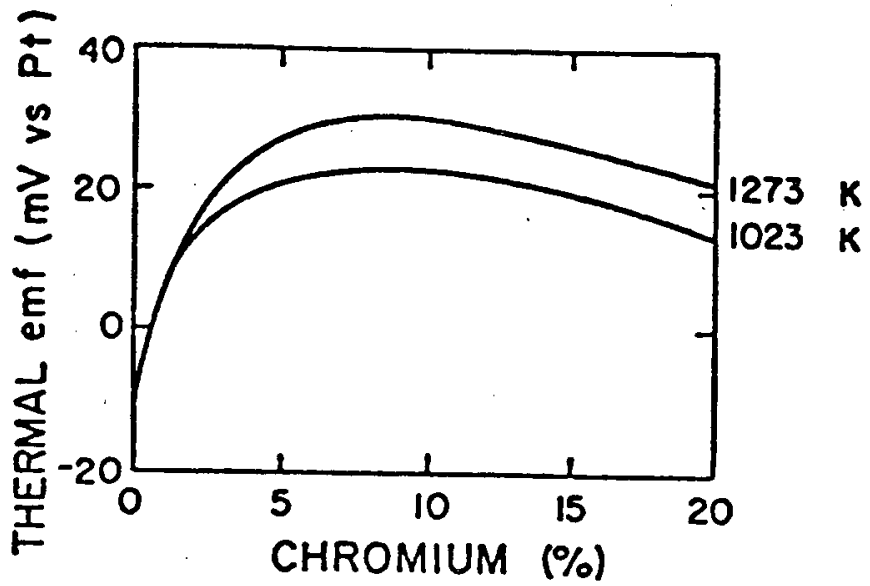

Fig. 7e. Effect of $\mathrm{Cr}$ content on thermoemf of $\mathrm{Ni}-\mathrm{Cr}$ alloy (Ref. temp $=$ 298 K) (Ref. 54).

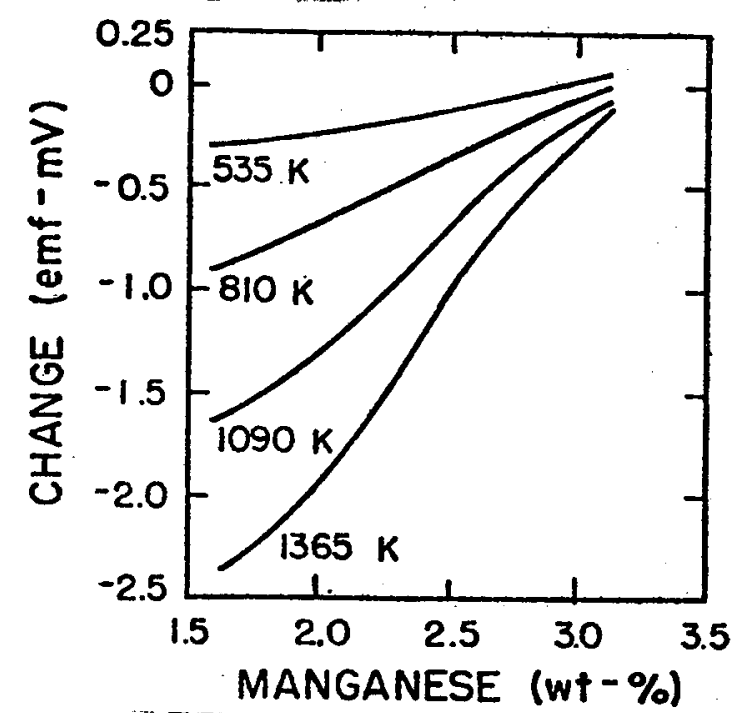

Fig. 7g. Effect of Mn on the emf change of Ni-Al alloy (Nial) (Ref. 26). 


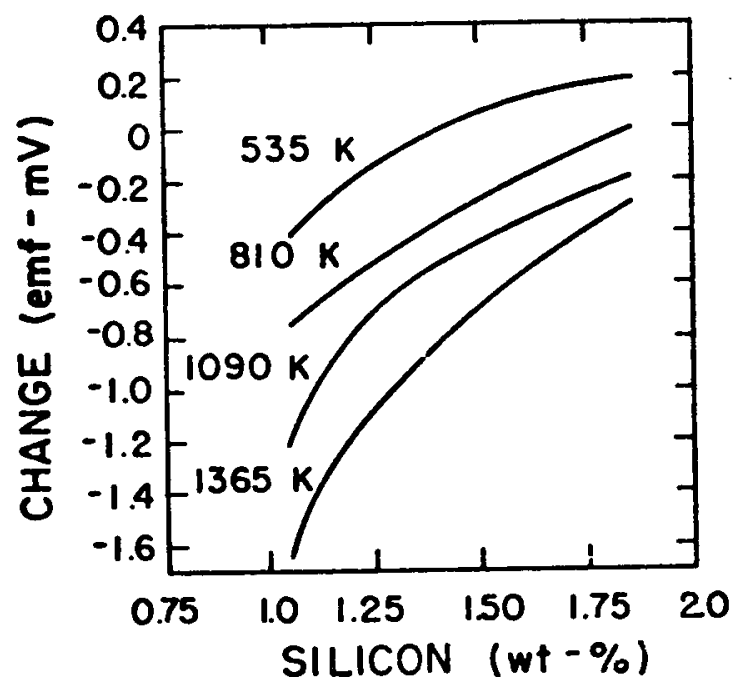

Fig. 7h. Effect of Si on the emf change of $\mathrm{Ni}-\mathrm{Al}$ alloy (Nial) (Ref. 26).

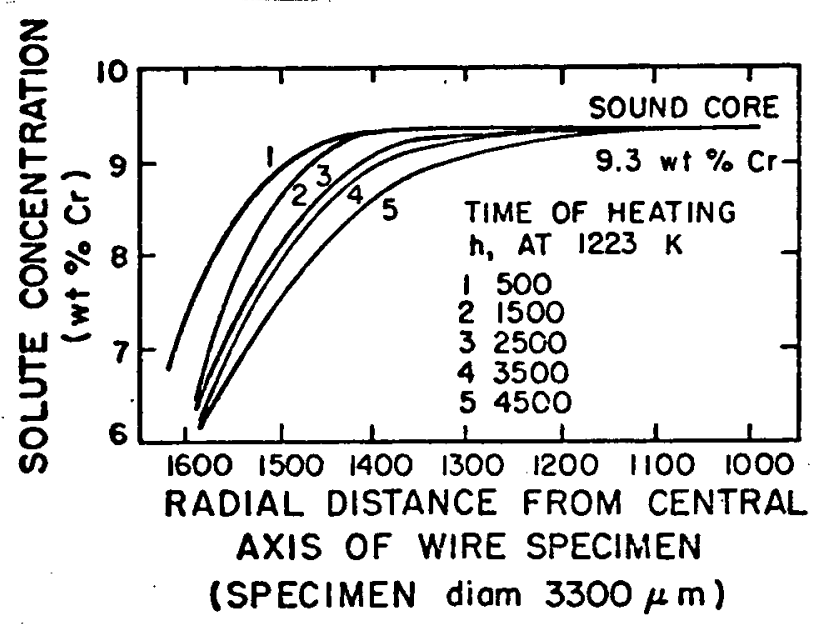

Fig. 8a. $\mathrm{Cr}$ concentration in the zone of solute depletion in

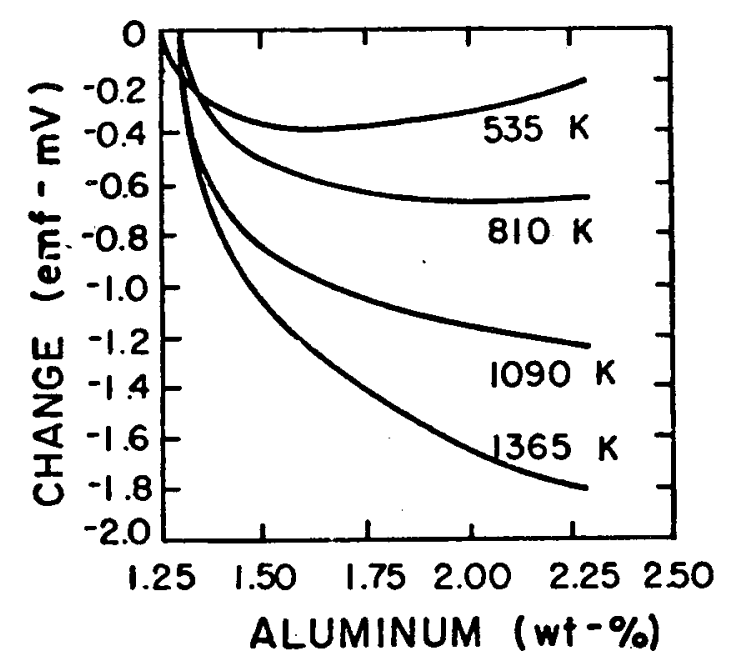

Fig. 7i. Effect of $A 1$ on the emf change of $\mathrm{Ni}-\mathrm{Al}$ alloy (Nial) (Ref. 26).

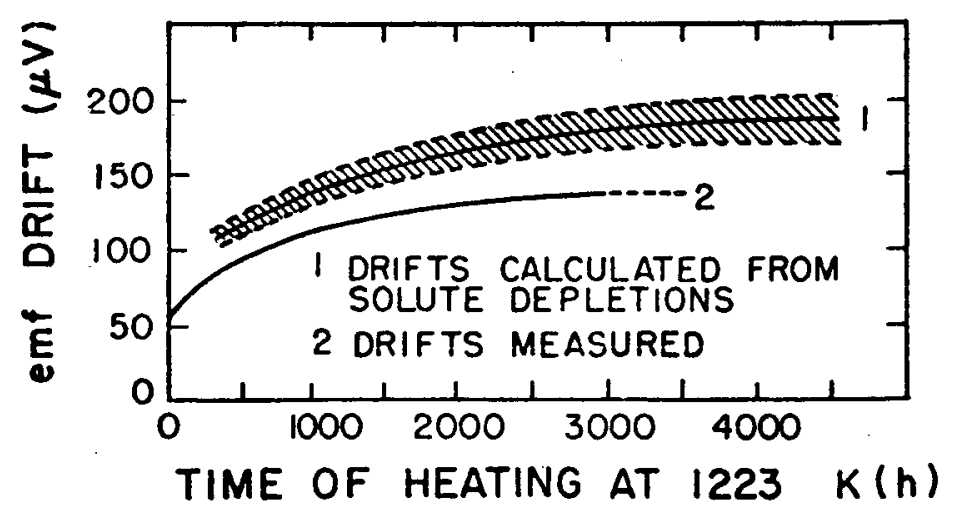

Fig. 8b. Comparison of calculated and measured values of thermo-emf drift in $\mathrm{Ni}-\mathrm{Cr}$ alloy (Ref. 15). 


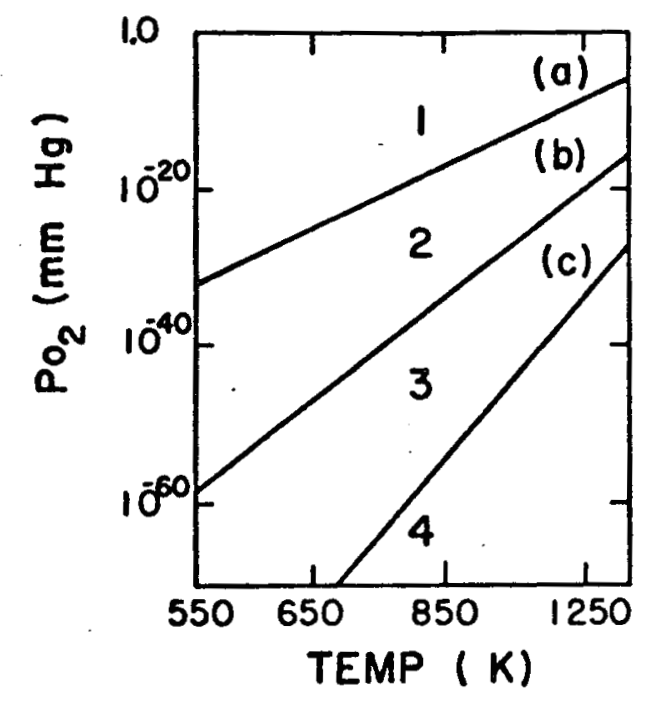

$$
\begin{aligned}
& \text { Reaction for curve (a) } 2 \mathrm{NiO} \rightleftharpoons 2 \mathrm{Ni}+\mathrm{O}_{2} \\
& \text { (b) } 2 / 3 \mathrm{Cr}_{2} \mathrm{O}_{3} \rightleftharpoons 4 / 3 \mathrm{Cr}+\mathrm{O}_{2} \\
& \text { (c) } 2 / 3 \mathrm{Al}_{2} \mathrm{O}_{3} \rightleftharpoons 4 / 3 \mathrm{Al}+\mathrm{O}_{2}
\end{aligned}
$$

Area 1 - Oxidizing to $\mathrm{Ni}, \mathrm{Cr}$ and $\mathrm{AT}$ :

2 - Oxidizing to $\mathrm{Cr}$ and $\mathrm{Al}$ Reducing to $\mathrm{NiO}$

3 - Oxidizing to $\mathrm{Al}$ Reducing to $\mathrm{NiO}$

Reducing to $\mathrm{Cr}_{2} \mathrm{O}_{3}$

4 - Reducing to $\mathrm{Al}_{2} \mathrm{O}_{3}, \mathrm{NiO}, \mathrm{Cr}_{2} \mathrm{O}_{3}$

Fig. 9. Reaction equilibrium: relation between $\mathrm{Po}_{2}$ and temperature (Ref. 13).

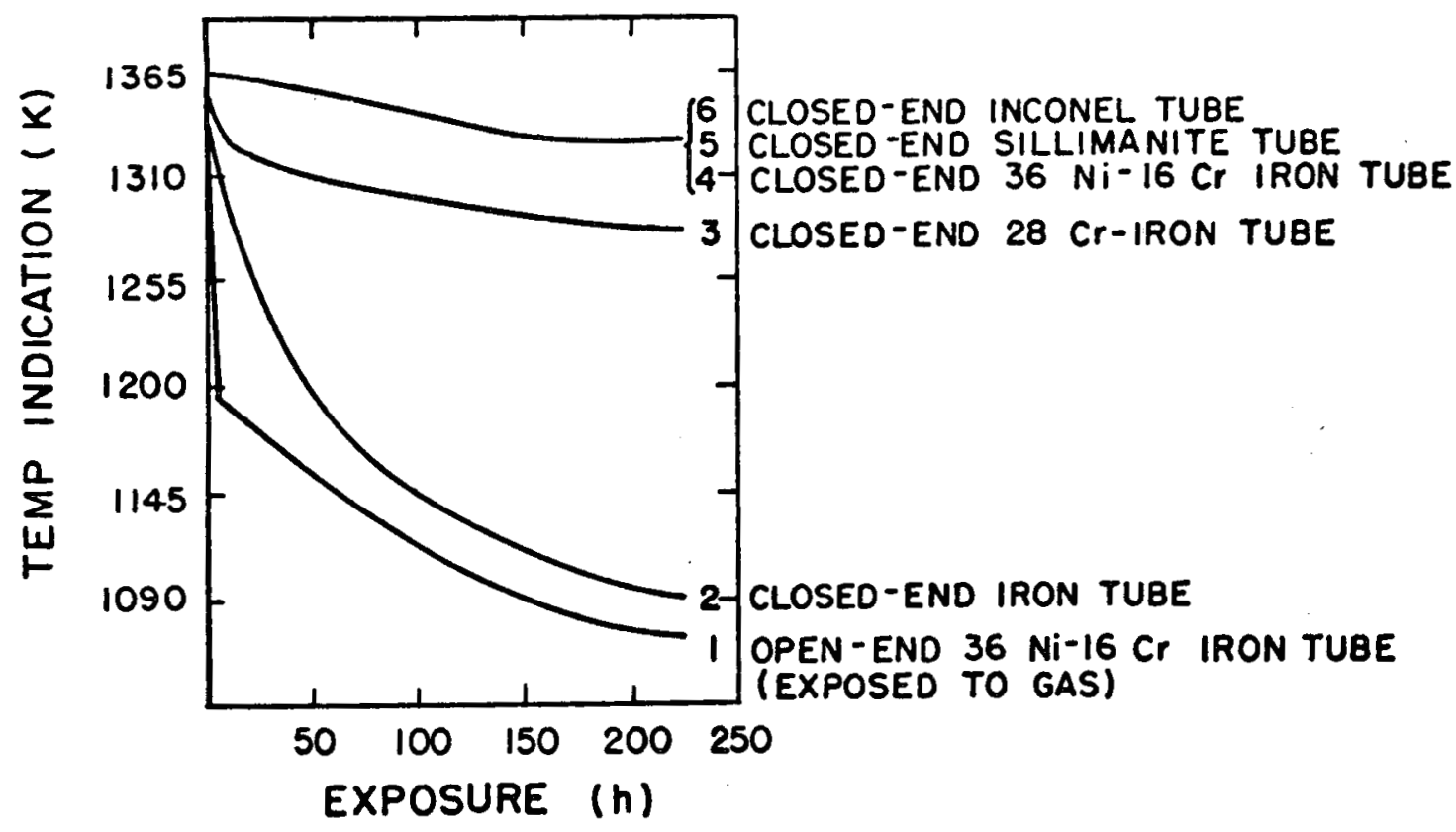

Fig. 10. Changes in indicated temperature of 1.0- $\mathrm{mm}$ Chrome1-Alumel thermocouples in protection tubes and exposed to rich exothermic gas at $1366 \mathrm{k}$ (Ref. 19). 


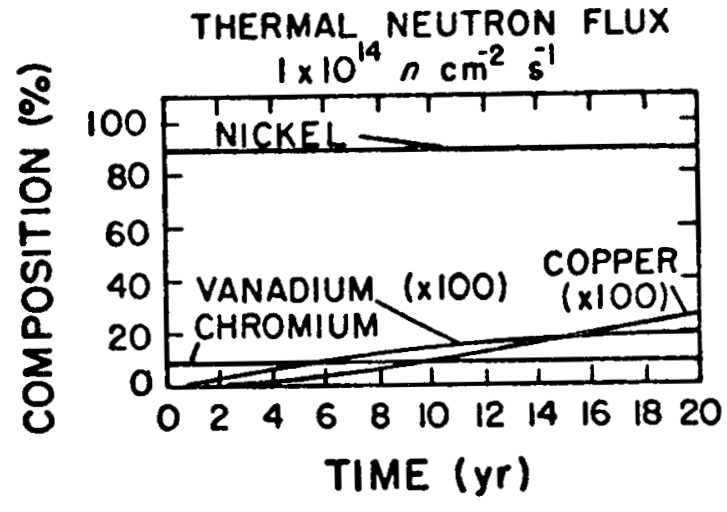

Fig. 11a, Chromel composition changes by transmutation (Ref, 20).

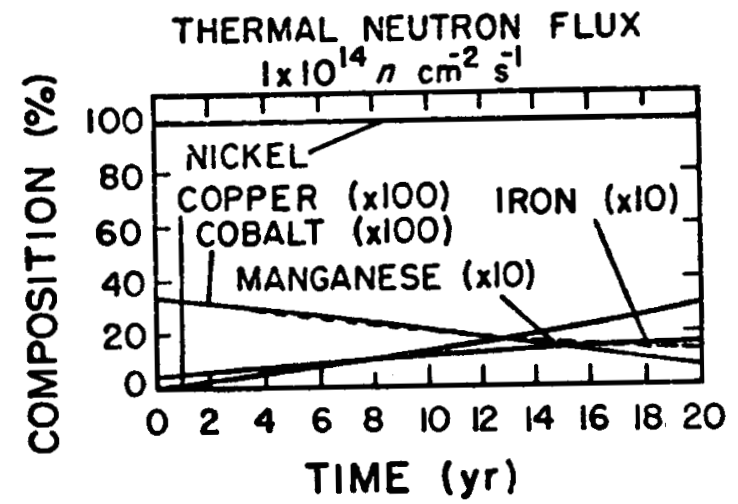

Fig. 11b. Alumel composition changes by transmutation (Ref. 20).

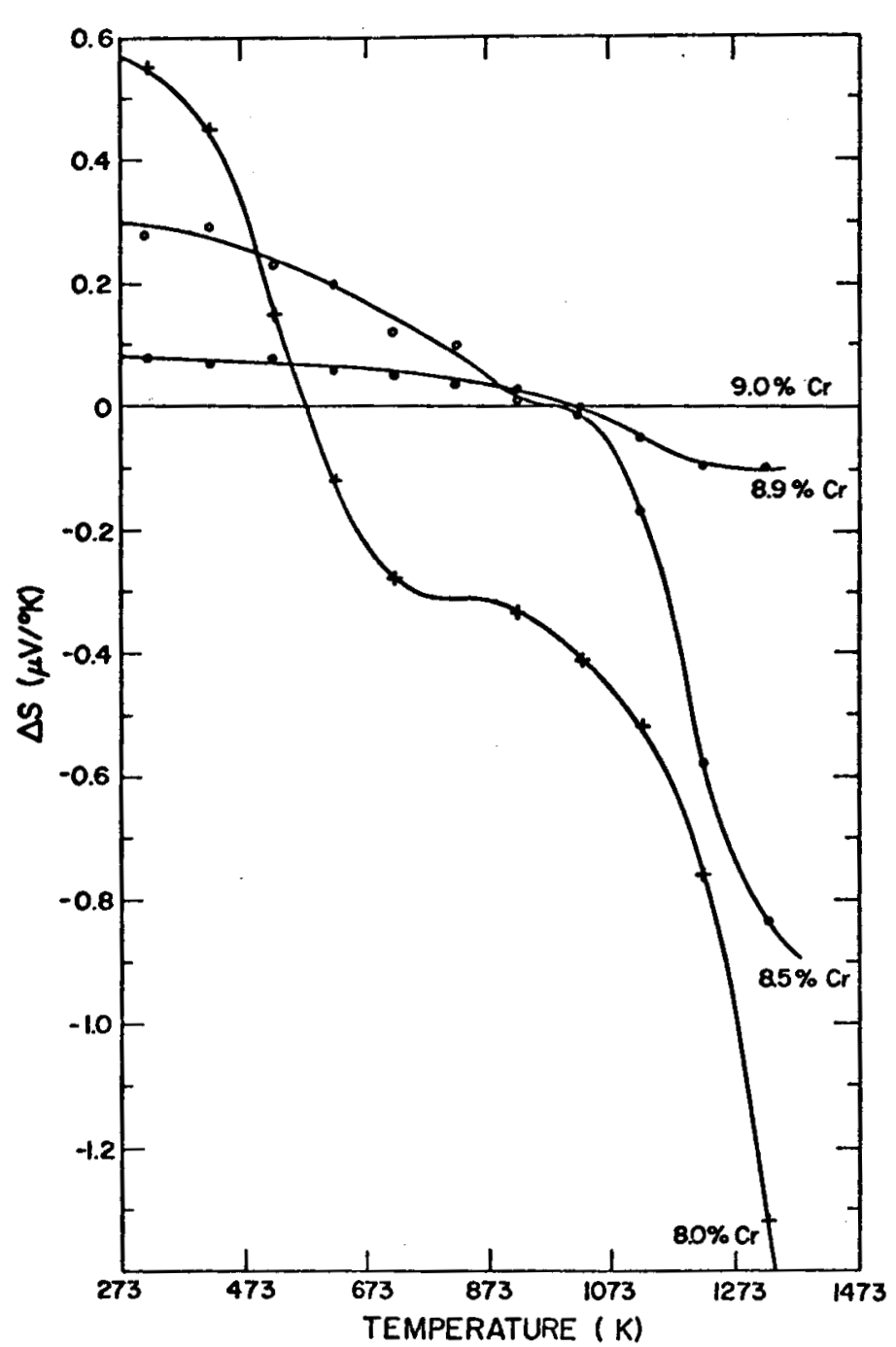

Fig. 12a. Change in Seebeck coefficient with $\mathrm{Cr}$ depletion in $\mathrm{Ni}-\mathrm{Cr}$ alloy. 


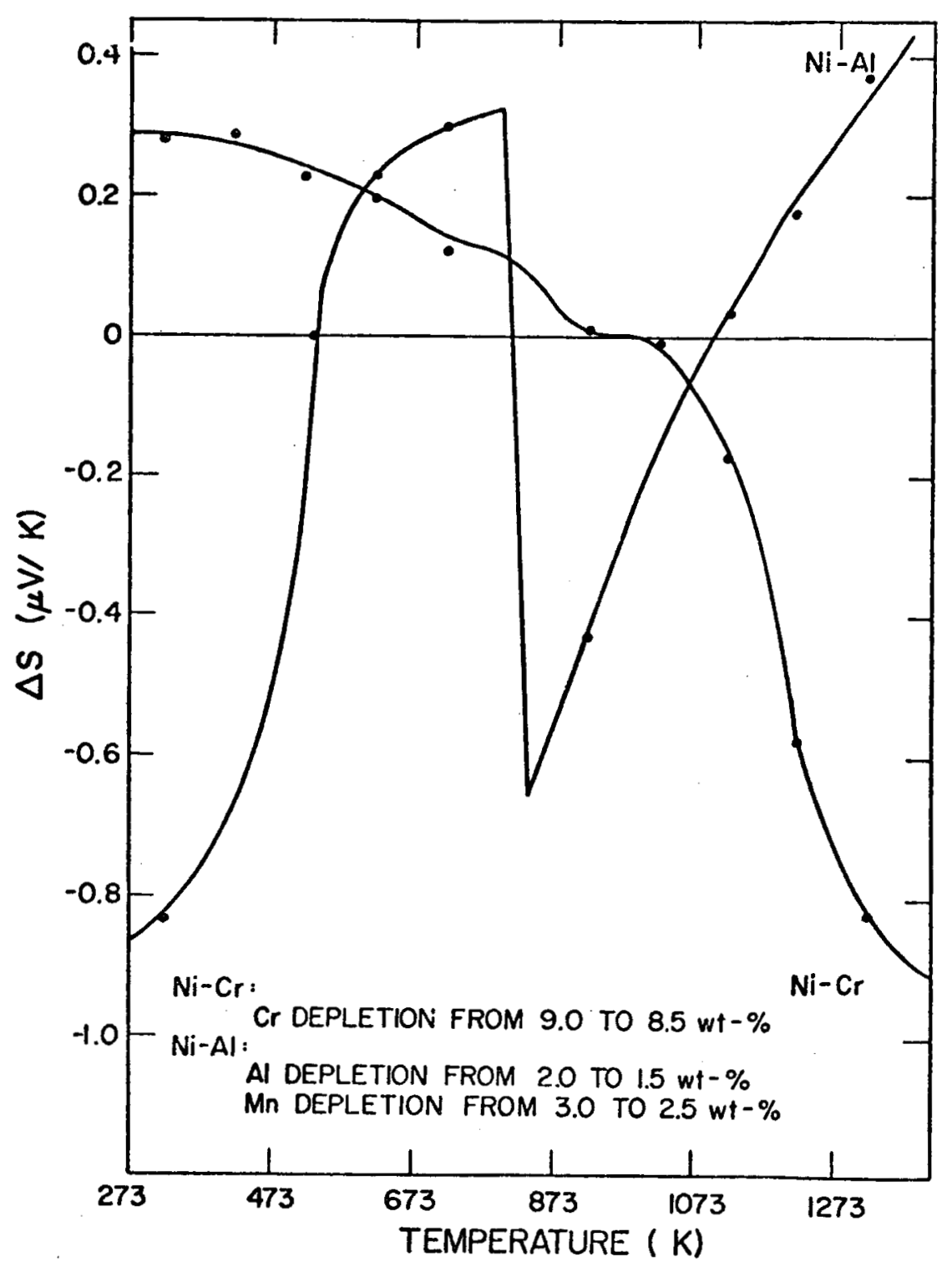

Fig. 12b. Change in Seebeck coefficient with solute depletion in $\mathrm{Ni}-\mathrm{Cr}$ and $\mathrm{Ni}-\mathrm{Al}$ alloys.

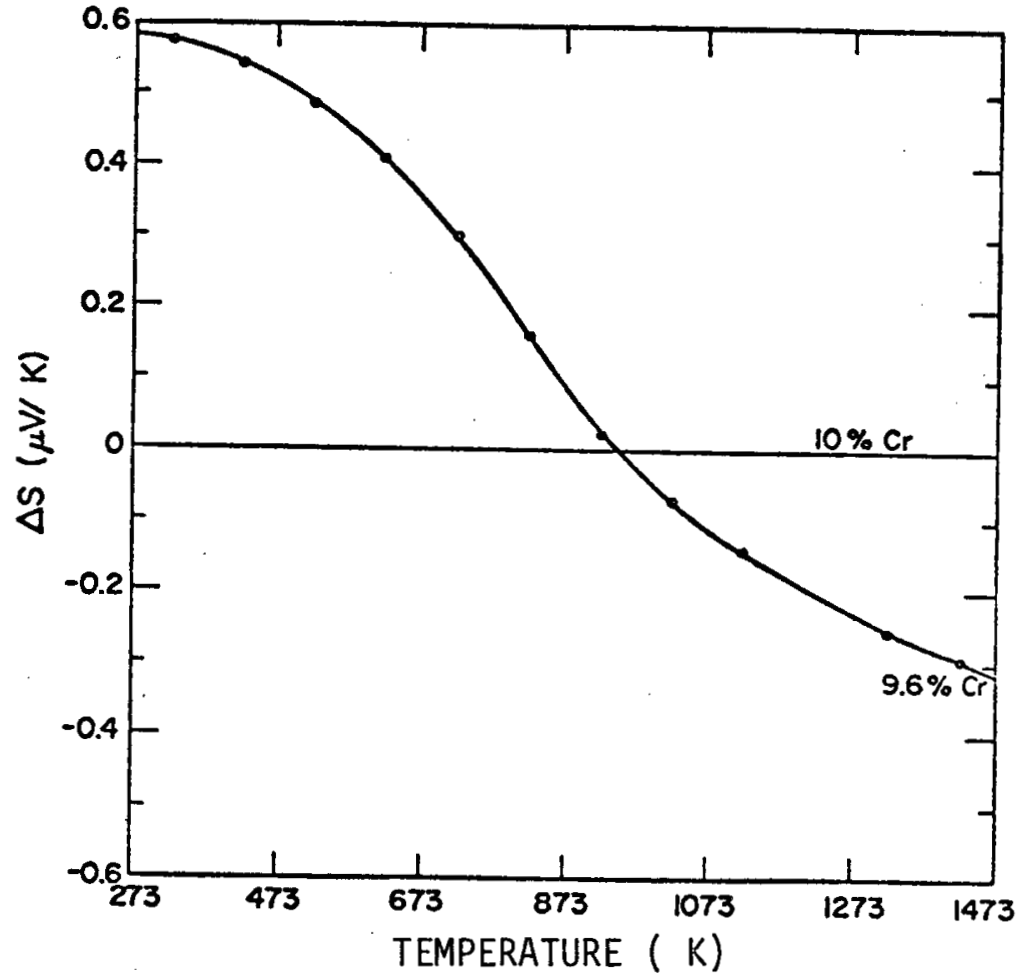

Fig. 12c. Change in Seebeck coefficient with $\mathrm{Cr}$ depletion in $\mathrm{Ni}-\mathrm{Cr}$ alloy. 


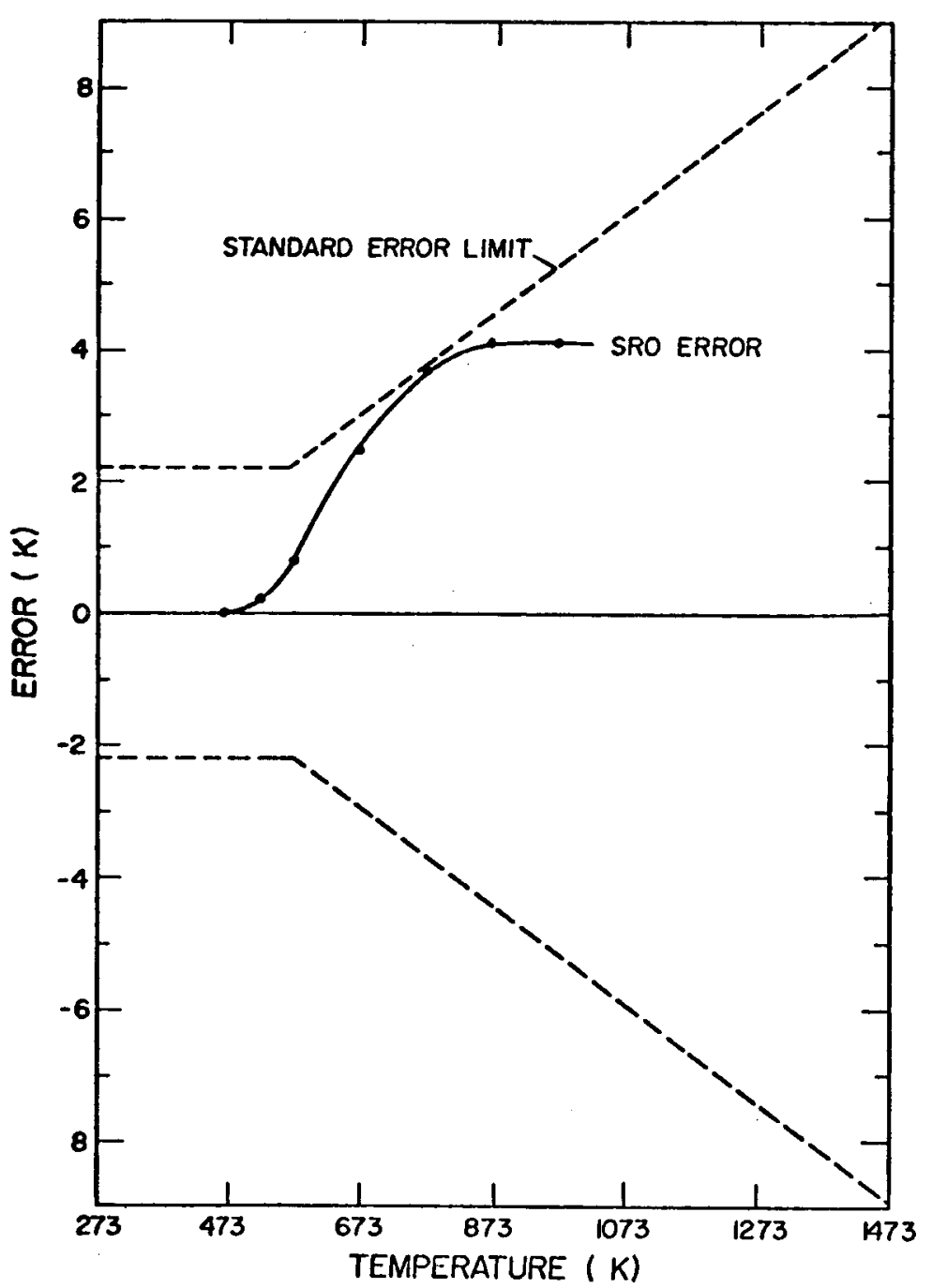

Fig. 13. Short-range ordering error in Alumel error limits.

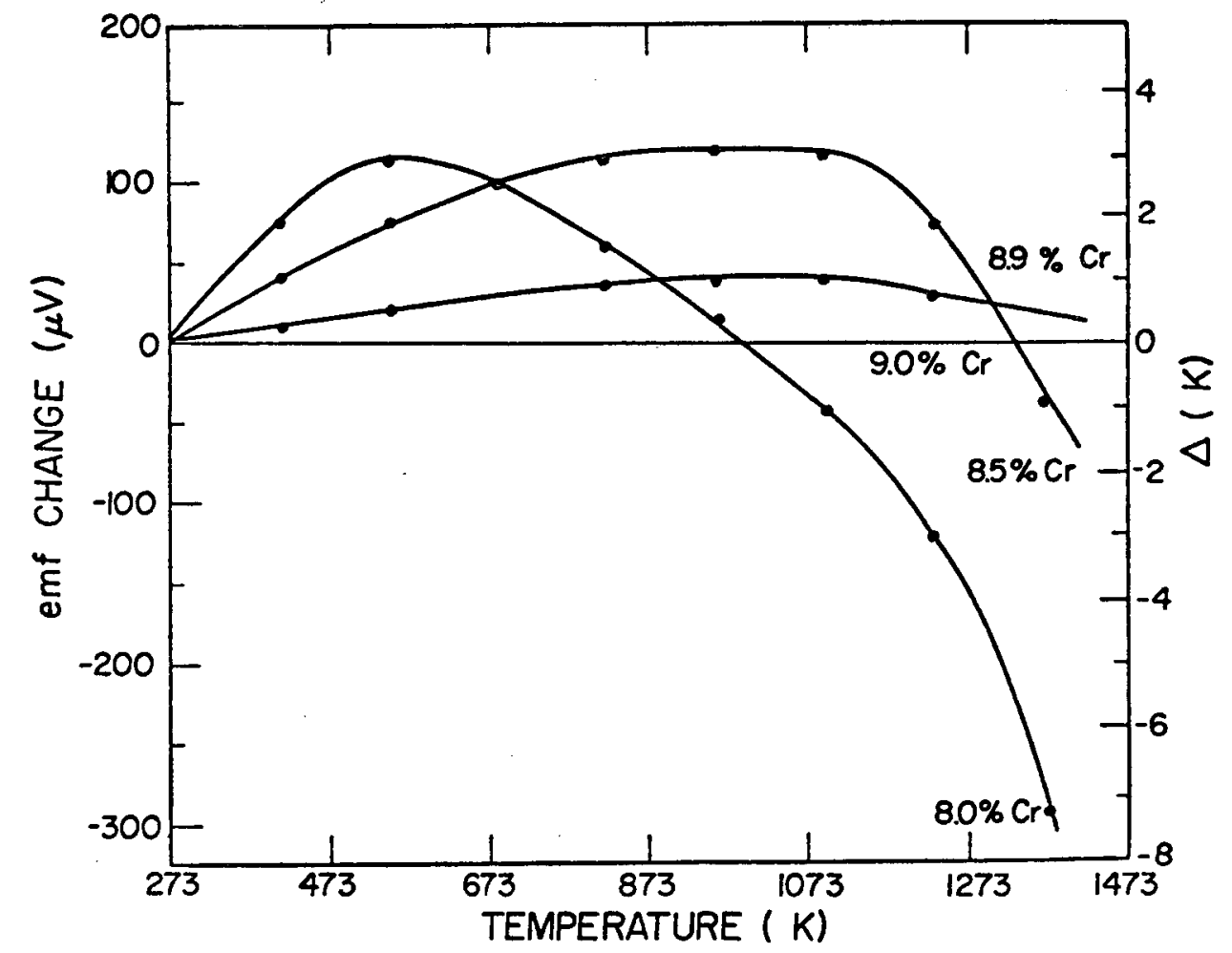

Fig. 14a. Change in thermo-emf with $\mathrm{Cr}$ depletion in $\mathrm{Ni}-\mathrm{Cr}$ alloy. 


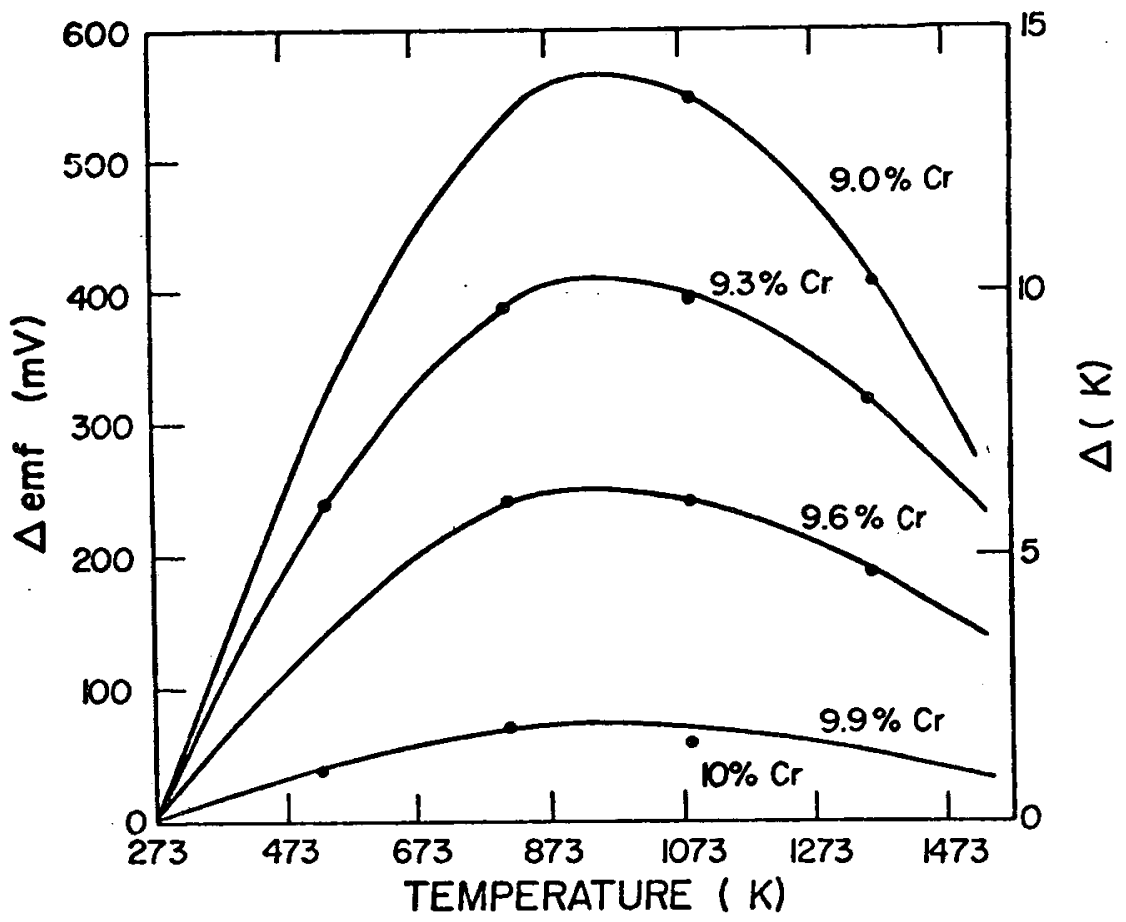

Fig. 14b. Emf and temperature errors with $\mathrm{Cr}$ depletion in $\mathrm{Ni}-\mathrm{Cr}$ alloy ( $10 \mathrm{wt} \%$ $\mathrm{Cr}$ initial concentration).

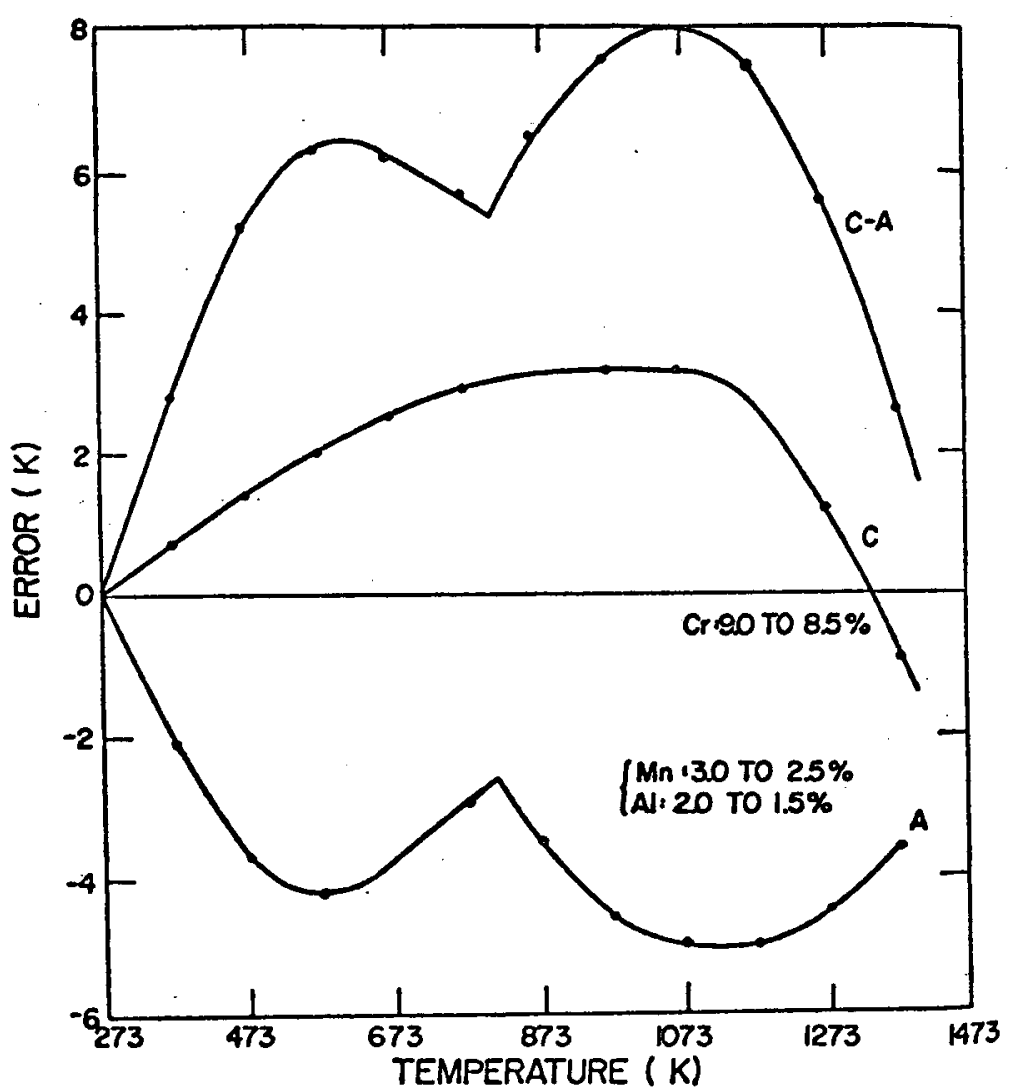

Fig. 14c. Temperature measurement error for typical solute depletions in Chromel (C) and Alumel (A). 


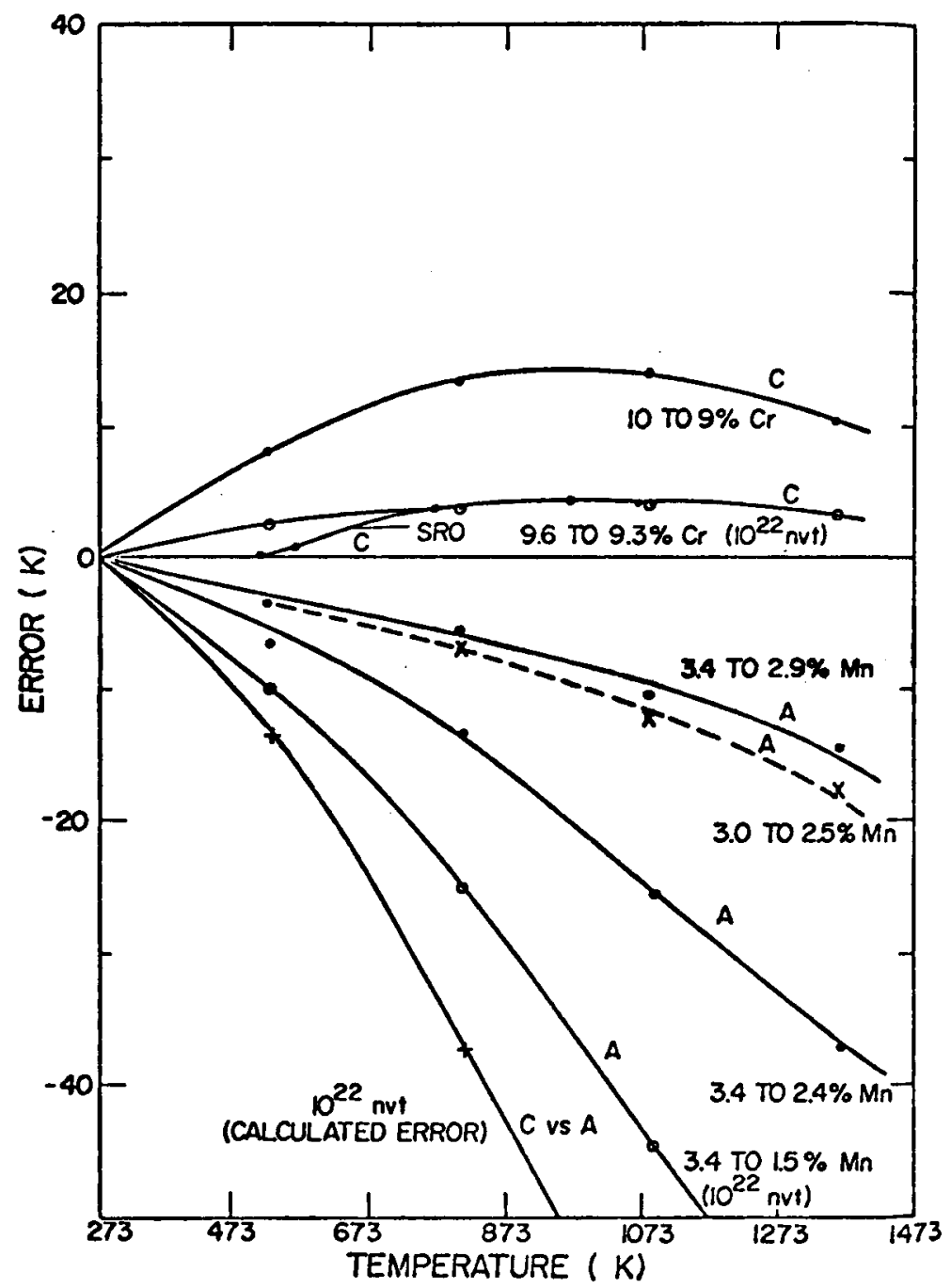

Fig. 15. Thermo-emf errors for solute depletions and nuclear transmutations in Chromel (C) and

Alume $1(A)$.
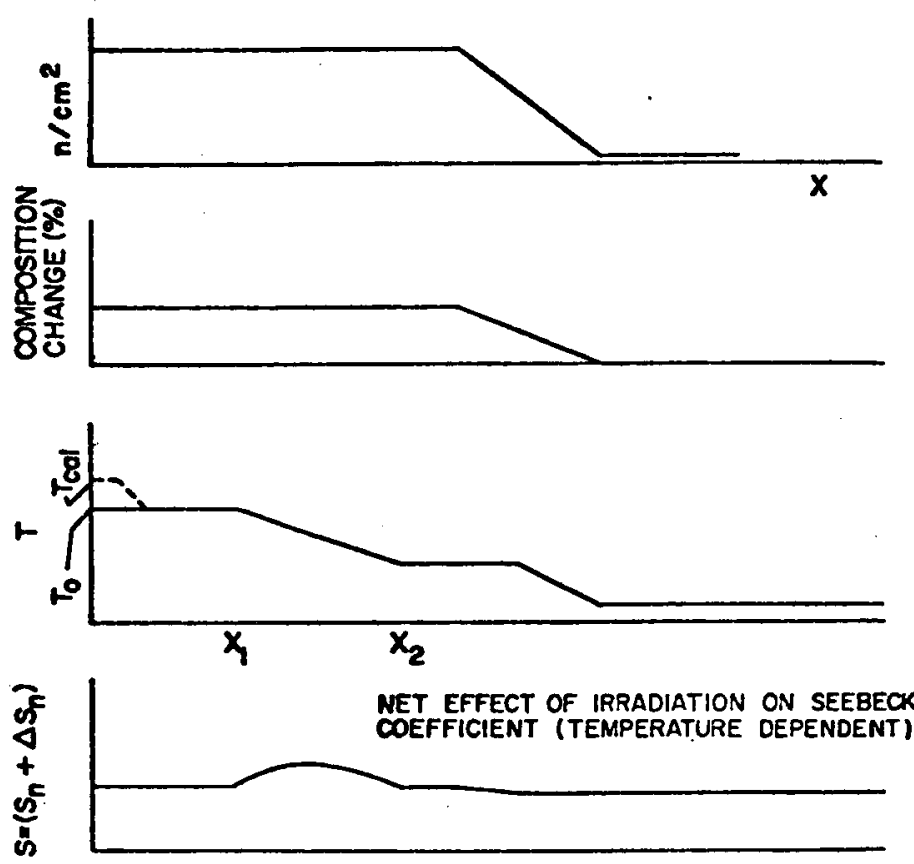

1. HOMOGENEOUS CONDUCTORS, $T_{0}\left(S=S_{n}=\right.$ CONSTANT $)$. IDEAL 2. HOMOGENEOUS CONOUCTORS, $T$ CASE 3. IRRADIATION-IMPOSED INHOMOGENITY, $\left.T_{0}\left(S=S_{n}+\Delta S_{n}\right)\right\}$ CASE
4. IRRADIATION-IMPOSED INHOMOGENITY, $T_{\text {COI }}$

$\boldsymbol{w}$

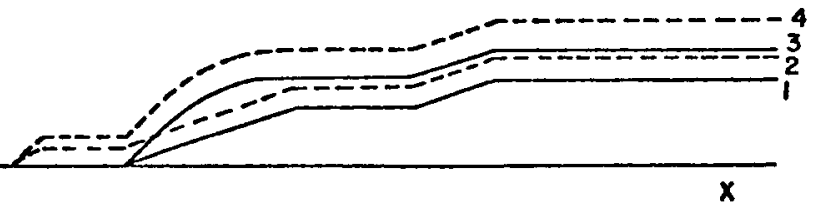

Fig. 16a. In situ calibration; correct method. 


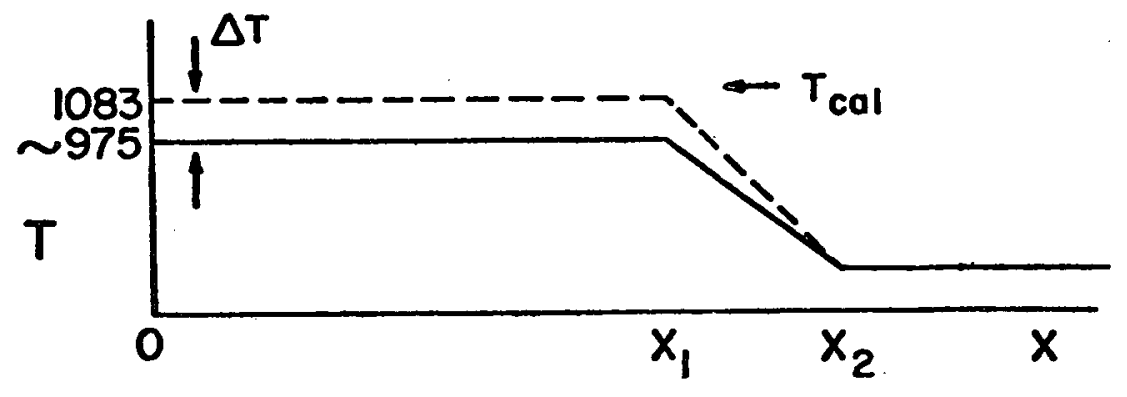

$\mathbf{S}$

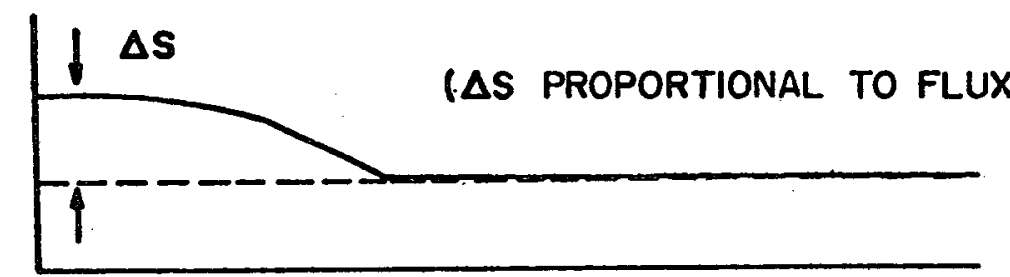

$E$

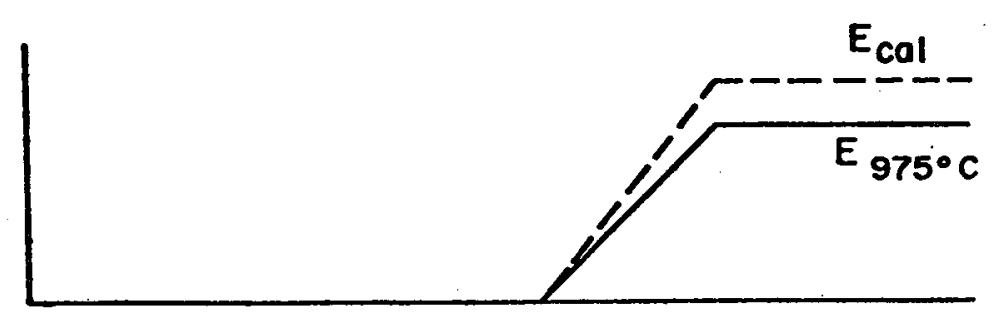

Fig. 16b. In situ calibration; incorrect method.

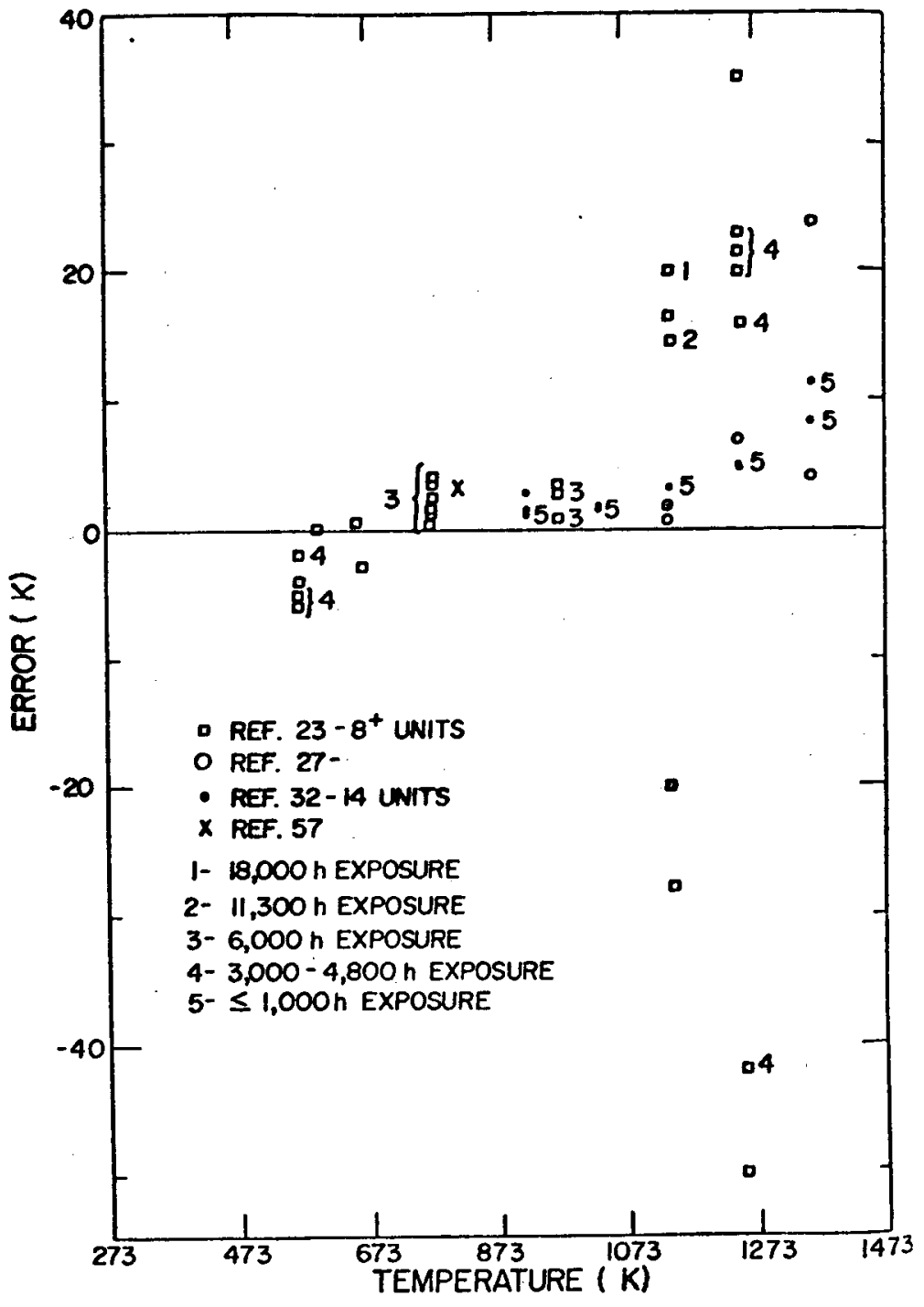

Fig. 17. Observed errors for unprotected Chromel-Alumel thermocouples heated in air. 


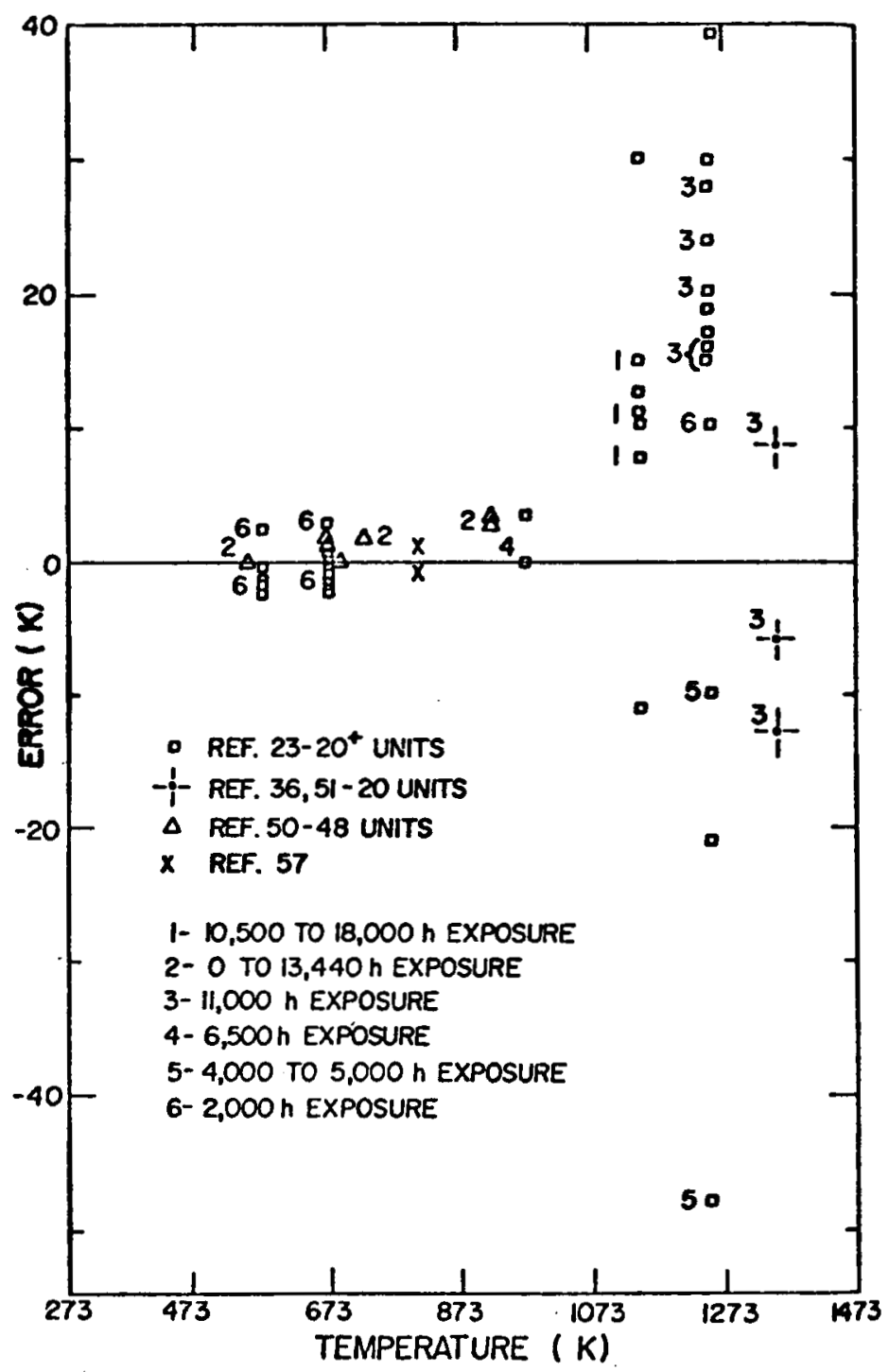

Fig. 18. Observed errors for sheathed Chromel-Alumel thermocouples.

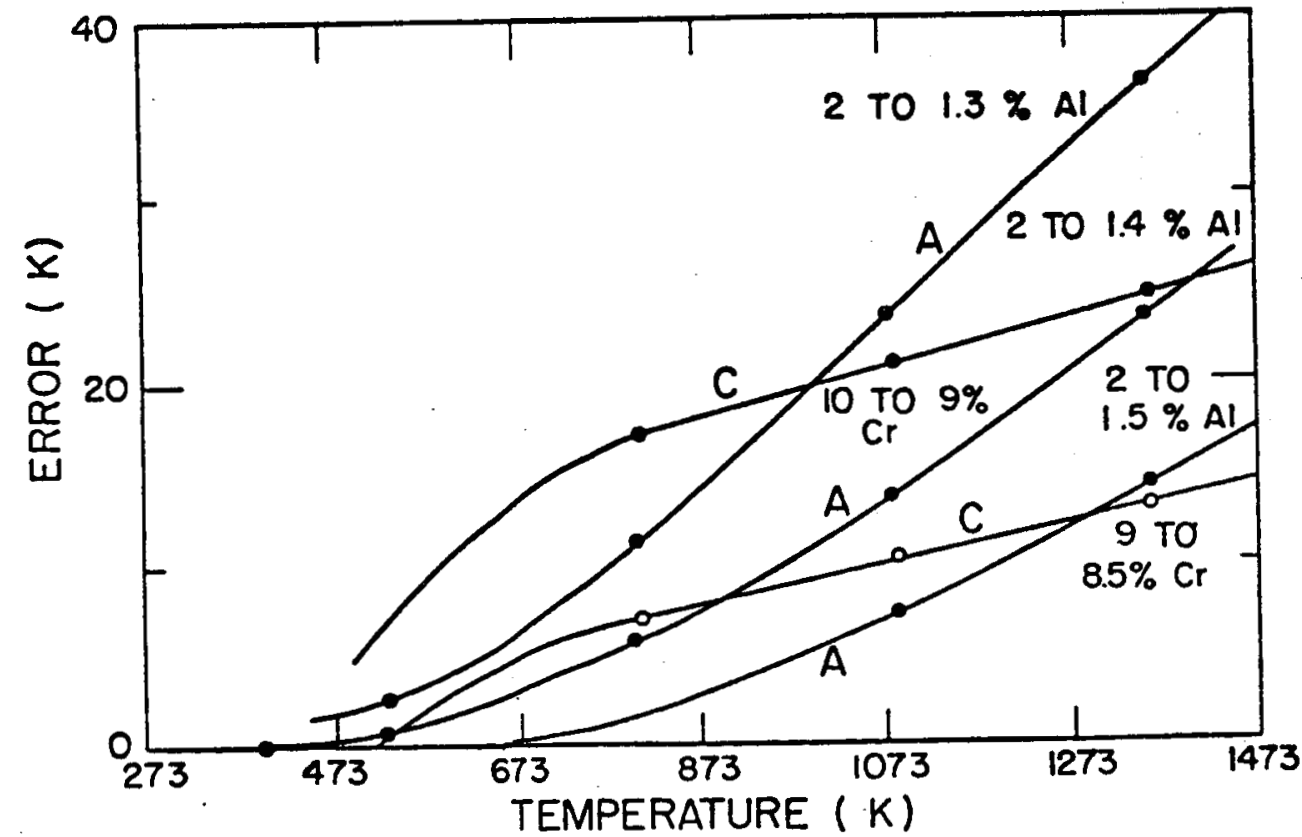

Fig. 19. Temperature measurement errors for aluminum depletion in Alumel (A) and chromium depletion in Chromel (C). 


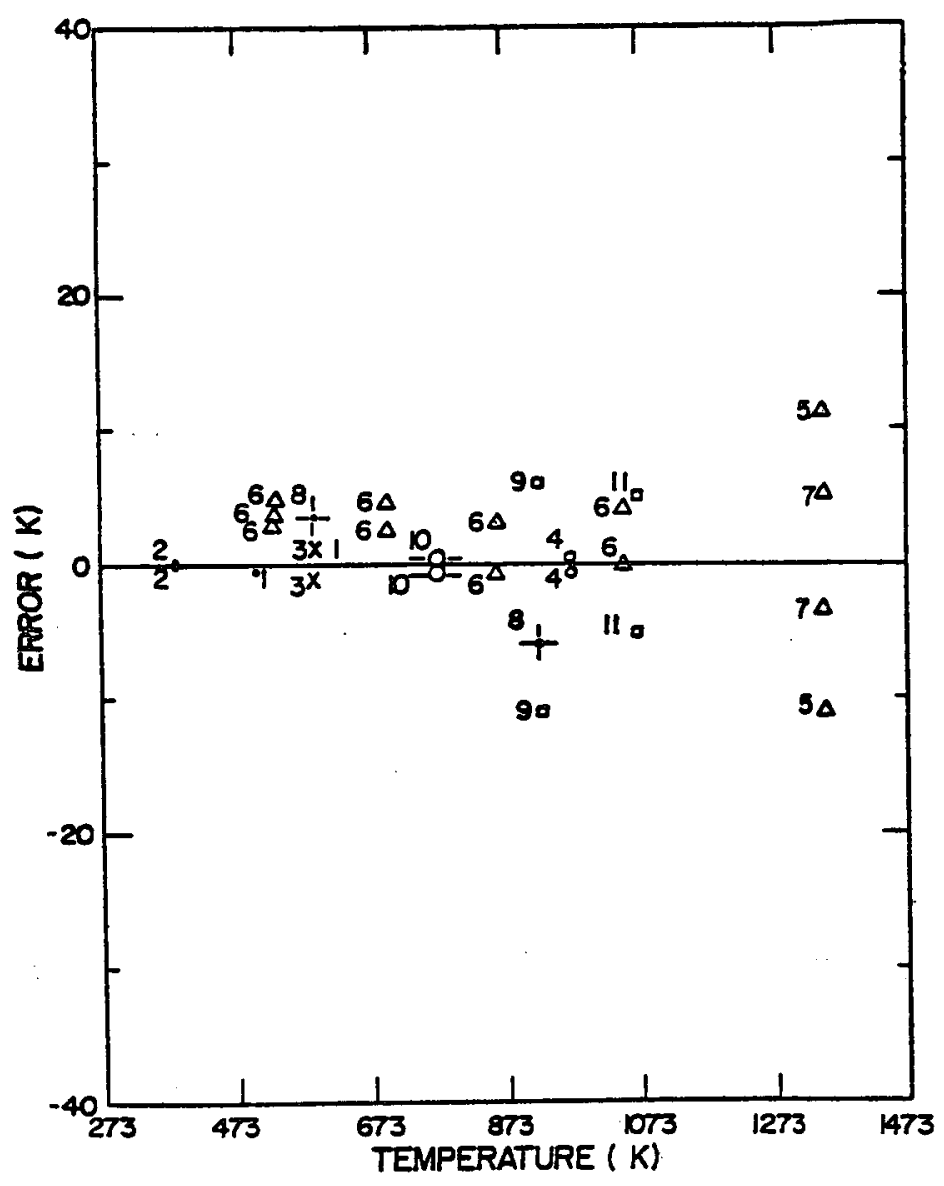

SWEOL SOURCE CONOITIONS

1. - Ref. 53 One unit; $2 \times 10^{10} n / \mathrm{com}^{2}$ (thental); in

situ calibration

2. Ref. 55 One unit; $2 \times 10^{19} \mathrm{n} / \mathrm{cm}^{2}$ (therme1); pre

3. $x$ Ref. 57 Unspecifled

4. 0 Ref. 56

One unit; irradtation at 923 to $973 \mathrm{~K}$. (thermal: pre and post irradiation caltbration

5. $\triangle \quad$ Ref. 58 One uniti irradiation at $1198 \mathrm{~K}$ for (thermal); in situ calibration

6. $\Delta$ Ref. 59 Four units; frradtation at 533 to $855 \mathrm{~K}$. $4.3 \times 10^{20} \mathrm{n} / \mathrm{cm}^{2}$ (fast), $4.5 \times 10^{21} \mathrm{n} / \mathrm{G}$ (thermal); pre and post irrediation

7. 4 Ref. 48

Two units; irradiation at $1228 \mathrm{~K}$ for $1.6 \times 10^{21} \mathrm{n} / \mathrm{cm}^{2}$ (the 1 ) in situ calibration
8. -:-
Ref. 28
Twenty-tow units; irradiation to
$7 \times 10^{2} \mathrm{n} / \mathrm{ax}^{2}$ (fast); pre and post irradiation calibration

9. 口

Ref. 60

10. - - -

Ref. 47

11. 口

Ref. 27
(p. 140$)$

1073 units; trradiatton at>758 $\mathrm{K}$.

$30850 \mathrm{~h}, 6 \times 10^{13} \mathrm{n} / \mathrm{cm}^{2}$ (fast)
$3.8 \times 10^{i 3} \mathrm{n} / \mathrm{cm}^{2}$ (thermat); 10 fallures: $3.8 \times 10 \mathrm{n} / \mathrm{cm}^{2} / \mathrm{ch}$

$800^{+}$units; irradiation unknown;

caltbration unknow

Detall unspecified; in situ callbration

Fig. 20. Observed errors for irradiated Chromel-Alume1 thermocouples. 